\title{
纳米零价铁富集水溶液中铀的表面化学及应用展望
}

\author{
滑熠龙 ${ }^{a, b}$ 李冬涵 $b$ 顾天航 ${ }^{c}$ 王伟 $c$ 李若繁 $c$ \\ 杨建平*, $a$ 张伟贤*,c,d \\ ( $a$ 东华大学材料科学与工程学院 上海 200051) \\ ( $b$ 南华大学资源环境与安全工程学院 衡阳 421001) \\ ( ${ }^{c}$ 同济大学污染控制与资源化研究国家重点实验室 上海 200092) \\ ( $d$ 华南农业大学 岭南现代农业科学与技术广东省实验室 广州 510642)
}

\begin{abstract}
摘要 由于铀矿采冶、核能利用等类活动的影响, 铀引起的水体污染问题日益严重. 纳米零价铁(nanoscale zero-valent iron, nZVI)及其复合材料可高效富集水溶液中低浓度的铀，在放射性废水的处理与铀的资源回收方面具有巨大的应用 潜力. 但是, 不同研究对 nZVI 分离铀的机理和性能尚未形成一致的解释. 因此, 本综述归纳了 nZVI 分离铀的研究进 展, 概括了溶液及固相反应机理(如吸附作用、还原作用、沉淀作用), 重点分析了水质因素(如 $\mathrm{pH} 、 \mathrm{U}(\mathrm{VI})$ 浓度、阳离 子、阴离子、溶解氧)的影响机制. 后续研究可注重分析铀废水中 nZVI 的结构转化规律及水质因素的协同作用对 nZVI 固定铀的机理、性能的影响; 并基于放射性废水的水质或水处理工艺的特征, 优化 nZVI 材料结构且评估其处理放射性 废水的长期稳定性和生态毒性; 确定 nZVI 固定铀的性能与水质组分及水处理工艺运行参数的数学相关性, 建立监测 和调控工艺的方法.
\end{abstract}

关键词 纳米零价铁; 铀; 放射性废水; 反应机理; 水质因素

\section{Enrichment of Uranium from Aqueous Solutions with Nanoscale Zero-valent Iron: Surface Chemistry and Application Prospect}

\author{
Yilong $\mathrm{Hua}^{a, b}$ \\ Donghan $\mathrm{Li}^{b}$ \\ Jianping Yang*,a \\ Tianhang $\mathrm{Gu}^{c}$ \\ Wei Wang ${ }^{c}$ \\ Ruofan $\mathrm{Li}^{c}$ \\ ( ${ }^{a}$ College of Materials Science and Engineering, Donghua University, Shanghai 200051, China)
}

( ${ }^{b}$ School of Resource Environment and Safety Engineering, University of South China, Hengyang 421001, China)

(c State Key Laboratory of Pollution Control and Resource Reuse, Tongji University, Shanghai 200092, China)

( ${ }^{d}$ Guangdong Laboratory for Lingnan Modern Agriculture, South China Agricultural University, Guangzhou 510642, China)

\begin{abstract}
In the processes of uranium mining and nuclear power utilization, water pollution caused by radioactive contaminants (e.g., uranium) is becoming increasingly serious. Nanoscale zero-valent iron (nZVI) and its composites can be used to enrich low-concentrated uranium ions from radioactive wastewater effectively. Published works have demonstrated that nZVI has great application potential to treat uranium-contanined radioactive wastewater. However, published researches on the performance and mechanisms for U(VI) immobilization by nZVI between different papers are not unanimous. Based on the research progress, this review summarizes the aqueous and solid reaction mechanisms (e.g., adsorption, reduction and precipitation) between nZVI and $\mathrm{U}(\mathrm{VI})$ ions, and specifically discusses the effects of solution factors (e.g., $\mathrm{pH}, \mathrm{U}(\mathrm{VI})$ concentration, cations, anions and dissolved oxygen) on U(VI) immobilization. Before the field-scale application of nZVI to remedy uranium wastewater, deep researches should be conducted to investigate: (i) the phase transformation of nZVI in uranium wastewater and the synergistic effect of solution factors on the ability of nZVI to separate uranium; (ii) based on the characteristics of radioactive solution and wastewater treatment processes, the structure of nZVI particles needs to be optimized and their long-term stability and ecotoxicity needs to be evaluated; (iii) confirm the mathematical correlation between the performation of nZVI to immobilize uranium and wastewater components and operation parameters, and then extabilish the monitoring and regulating method for wastewater treatment technology.
\end{abstract}

Keywords nanoscale zero-valent iron; uranium; radioactive wastewater; reaction mechanism; solution factor

*E-mail: jianpingyang@dhu.edu.cn; zhangwx@tongji.edu.cn

Received April 18, 2021; published June 29, 2021.

Project supported by the National Natural Science Foundation of China (Nos. 41772243, 51978488 and 21277102), the Research Foundation of Education Bureau of Hunan Province, China (No. 18C0432), the Natural Science Foundation of Hunan Province, China (No. 2020JJ5489) and the Key-Area Research and Development Program of Guangdong Province (No. 2020B0202080001).

项目受国家自然科学基金(Nos. 41772243, 51978488, 21277102)、湖南省教育厅基金(No. 18C0432)、湖南省自然科学基金(No. 2020JJ5489)和广东省重 点领域研发计划项目(No. 2020B0202080001)资助. 


\section{1 引言}

铀矿开采与核能利用过程中的安全事故导致水环 境中铀的含量远超自然本底值, 严重危害人类的身体健 康 ${ }^{[-9]}$. 日本福岛核电站事故(2011 年)产生的废水、废气、 固体废物向周边地区的大气、土壤和水体中释放大量 ${ }^{235} \mathrm{U} 、{ }^{127 \mathrm{~m}} \mathrm{Te} 、{ }^{132} \mathrm{Te} 、{ }^{131} \mathrm{I} 、{ }^{133} \mathrm{Xe} 、{ }^{134} \mathrm{Cs} 、{ }^{136} \mathrm{Cs} 、{ }^{137} \mathrm{Cs}$ 和 ${ }^{90} \mathrm{Sr}$ 等放射性物质 ${ }^{[10-14]}$. 至 2020 年 9 月, 该事故已产生 123 万吨放射性废水 ${ }^{[15]}$, 且以每天约 150 吨的速率持续 增加 ${ }^{[16]}$. 该事故对环境产生严重的放射性污染, 并对居 民的饮食安全、身体和心理健康产生显著的危害. 因此, 基于放射性污染物特有的物理、化学性质, 研发高性能 的环境修复材料并完善相关污染防控理论与技术可为 污染治理提供支撑.

相比于传统(非)生物材料, 纳米零价铁(nanoscale zero-valent iron, nZVI) 去除 $U(V I)$ 具有速率快、负荷高、 选择性强、产物稳定性强等优点. 国内外众多科研团队 已初步探索了简单或复杂环境体系中 nZVI 去除 U(VI) 的溶液及固相反应机制, 并研发多种 nZVI 复合材料及 含铀废水治理工艺 ${ }^{[17-51]}$. 但是, 不同学者对 nZVI 分离 $\mathrm{U}(\mathrm{VI})$ 的机制及水质因素的影响未形成一致的结论. 因 此, 本综述通过归纳 $\mathrm{nZVI}$ 分离水溶液中 $\mathrm{U}(\mathrm{VI})$ 的科研动 态, 重点讨论化学反应机理及阐明水质因素的影响, 并 对该技术的应用前景进行展望.

nZVI 为 “核-壳” 结构, 其壳层为铁氧化物, 核心为 单质铁. 单个 nZVI 颗粒粒径小 $(20 \sim 120 \mathrm{~nm})$ 、比表面积 大 $\left(35 \mathrm{~m}^{2} / \mathrm{g}\right)$ 、表面反应位点数量多且还原性强 ${ }^{[52]}$. 基于 其优良的物理化学反应活性, nZVI 可去除水溶液中有 机、无机污染物(如三氯乙烯 ${ }^{[53-54]}$ 、二氯乙烷 ${ }^{[5]}$ 、硝基

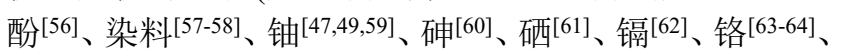
银 $\left.{ }^{[65-66]}\right)$. nZVI 与重金属的作用机理主要包括吸附、还原 和(共)沉淀(图 1). 首先, nZVI 中的铁氧化物层通过静电 作用和配位作用吸附(类)金属离子; 其次, $\mathrm{Fe}(0)$ 将氧化 性强的(类)金属离子还原至较低价态; 然后, $\mathrm{Fe}(0)$ 腐蚀

(a) nZVI固定重金属的微观机理
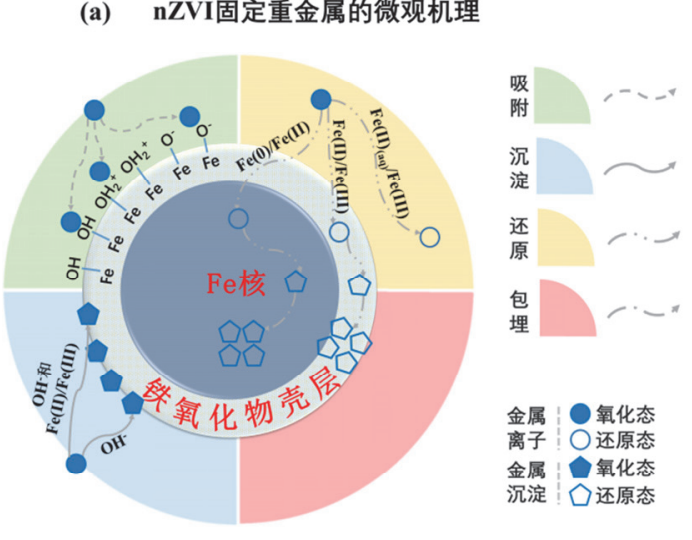

过程产生的氢氧根使体系为碱性; 最后, 铁腐蚀产生的 $\mathrm{Fe}(\mathrm{II})$ 和 $\mathrm{Fe}$ (III) 与(类)金属离子形成(共)沉淀 ${ }^{[67]}$. 多项 $\mathrm{nZVI}$ 处理重金属废水的中试及工程应用结果均已证明 nZVI 工艺去除污染物的效率高且经济成本低 ${ }^{[68-70]}$.

铀在水溶液中的迁移性能及毒性受其价态及水质 组分的影响. 氧化性条件下, 铀为 VI 价, 以 $\mathrm{UO}_{2}{ }^{2+}$ 及其 配合物的形式存在, U(VI) 类化合物迁移性及生态毒性 强; 在还原性条件下, $U(V I)$ 被还原为 $U(V)$ 或 U(IV), 其 迁移性及生态毒性显著降低. 在均相体系和非均相体系 中, nZVI 通过吸附、还原、(共)沉淀等机理将 U(VI)固定 在颗粒中而降低其对环境的危害 ${ }^{[41,49,71-75]}$. nZVI 去除 $\mathrm{U}(\mathrm{VI})$ 的性能及固相产物的稳定性受到铀废水水质组分 (如溶解氧、 $\mathrm{pH}$ 、阴离子、阳离子、有机物、微生物)的 影响. 不同学者研究了各因素对 U(VI)去除动力学、热 力学的影响, 并重点探索了 nZVI 颗粒中配合态、还原 态铀类化合物的结构、空间分布及长期稳定性 ${ }^{[71,76-78]}$. 相关研究结果表明, 应用 nZVI 治理含铀水体所面临的 主要难点问题包括 nZVI 颗粒易于团聚、电子供体传递 电子选择性低. 因此, 不同学者通过制备 nZVI-载体复 合材料或利用硫化试剂改性 nZVI 表面以提高其去除 $\mathrm{U}(\mathrm{VI})$ 的性能 ${ }^{[43,47,78-85]}$. Hua 等 ${ }^{[51]}$ 应用两级 nZVI 连续流工 艺处理铀尾矿库浸渍水, 研究结果证明出水铀的平均浓 度可由 $331 \mu \mathrm{g} / \mathrm{L}$ 降低至 $1.47 \mu \mathrm{g} / \mathrm{L}$ 并长期保持水质稳定. 但是, 由于各团队研究的侧重点、分析手段及实验初始 条件的差异, 不同研究得出的结论(如 $\mathrm{U}(\mathrm{VI})$ 去除动力学 特征、nZVI 分离 $\mathrm{U}(\mathrm{VI})$ 的主要机理、反应后 nZVI 颗粒 中铀的结构特征)不一致.

本综述全面分析讨论 nZVI 处理含铀废水的最新研 究进展. 该综述旨在: (1)回顾 nZVI 及其复合材料分离 溶液中 $\mathrm{U}(\mathrm{VI})$ 的研究概况; (2) 详述 nZVI 固定溶液中 $\mathrm{U}(\mathrm{VI})$ 的反应机理, 包括吸附、还原、沉淀等; (3)讨论含 铀废水水质因素影响 nZVI 去除 U(VI)的结果及原因. 通 过上述分析, 确定应用 nZVI 修复含铀废水所面临的理 论及工程难点, 对本领域技术的发展进行展望.

\section{(b) nZVI固定重金属的研究进展}

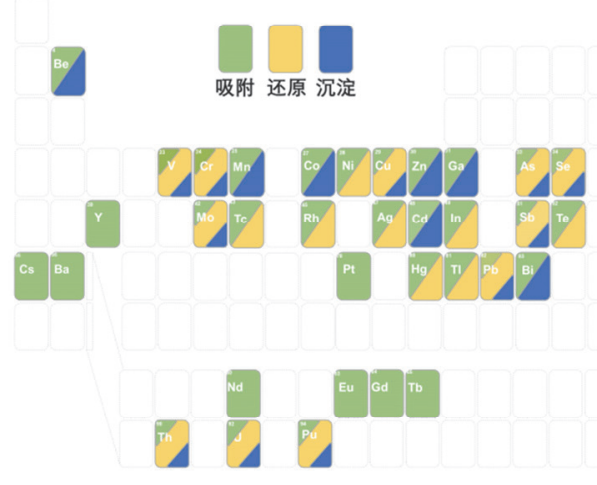

图 $1 \mathrm{nZVI}$ 与重金属反应机理及反应过程示意图

Figure 1 Schematic diagram of the heavy metal-nZVI reactions 


\section{$2 n Z V I$ 分离水溶液中铀的研究进展}

\section{1 研究概况}

近年来，应用 nZVI 修复含铀放射性废水已成为国 内外的研究热点(图 2). 1995 年, Cantrell 团队 ${ }^{[86]}$ 以 ZVI 为主要材料制备渗透墙修复含铀地下水, 证明单质铁通 过还原沉淀作用固定水溶液中的 U(VI). 2005 年, Burghardt 团队 ${ }^{[74]}$ 应用 nZVI 处理实际含铀放射性废水, 研究结果表明 nZVI 对 U(VI)的去除率接近 $100 \%$. 后续 研究致力于阐明简单或复杂水环境体系中 $n Z V I$ 分离 $\mathrm{U}(\mathrm{VI})$ 的机理并解决应用难题. 众多科研团队通过实验 分析和理论计算研究了单一或组合环境因素(如 $\mathrm{pH}$ 、 $\mathrm{U} / \mathrm{nZVI}$ 物质的量比、阴离子、阳离子、溶解氧、有机 物)对 nZVI 分离铀的性能及机理的影响, 并借助光谱、 电镜等技术从微观原子尺度探索了 nZVI 颗粒中铀的化 合价态、化学键成键方式和元素的空间分布特 征 ${ }^{[41,43,45-46,49-50,80,85,87]}$. 部分研究人员评估了 nZVI 去除 含铀地下水、铀矿山废水中 U(VI)的性能, 并验证了原 位/异位工艺净化含铀废水的性能 ${ }^{[35,51,77,83,88-92]}$.

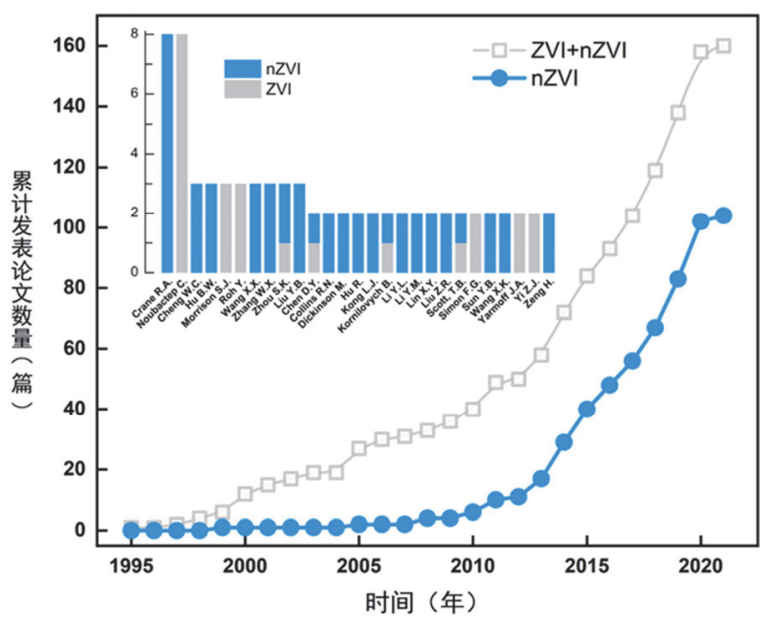

图 $21995 \sim 2021$ 年, nZVI 与水溶液中铀反应的研究性论文发表概况 (以第一通讯作者为代表进行统计, 截止 2021 年 1 月 31 日)

Figure 2 Research papers for the reactions between uranium and nZVI from 1995 2021 (Counted by the first corresponding author, January 31, 2021)

\section{2 研究内容}

应用 nZVI 及其复合材料处理含铀废水, 需解决以 下三个方面的理论及工程难题. 第一, nZVI 去除 U(VI) 的溶液化学及固相反应机理. 主要包括 U(VI)去除动力 学、热力学特征, 电子供体向 U(VI)传递电子的途径及 效率，反应后固相颗粒中铀化合物的种类、结构、空间 分布及稳定性, nZVI 及其复合材料的重复利用性能, 水 质组分与 $\mathrm{U}(\mathrm{VI})$ 去除性能/机理的相关性. 第二, nZVI 及 其复合材料的理化性质. 主要包括颗粒在水溶液中的迁 移性能, 表面官能团种类及配位性能, 铁氧化物种类及 结构转化规律等. 第三, 含铀废水处理工艺的调控机制 及模型. 如 nZVI 连续流工艺去除 U(VI)的性能, 关键控
制参数及其影响，工艺出水水质调控模型等.

\subsection{1 nZVI}

国内外研究结果表明, nZVI 与 U(VI)的反应过程为 吸热反应, 且该过程中 $U(V I)$ 浓度的变化符合准一级动 力学模型和 Langmuir 等温吸附模型. 应用 nZVI 修复含 铀废水, U(VI)的浓度可在数分钟内降低至 $1 \mu \mathrm{g} / \mathrm{L}, \mathrm{U}(\mathrm{VI})$ 的去除负荷达到 $2.4 \mathrm{~g} / \mathrm{g}^{[49]}$, 固液分配系数 $\left(K_{\mathrm{d}}\right)$ 比其他污 染物高 $1 \sim 2$ 个数量级 ${ }^{[51]}$. 反应后 $\mathrm{nZVI}$ 颗粒中的铀可吸 附在 nZVI 颗粒表面、富集在颗粒的核心区域并被铁氧

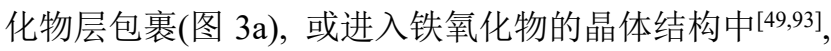
并且铀以还原态化合物 (如 $\mathrm{UO}_{2} 、 \mathrm{U}_{3} \mathrm{O}_{7}$ ) 为主(图 $3 \mathrm{~b}$, $3 c)^{[43,47-48,50,71-72,78,80,85,94-95]}$, 在不同碳酸氢盐条件下其反 应机理也有所差异(图 3d), 通过高角环形暗场-扫描透 射电子显微镜(HAADF-STEM)图像可清晰地看出反应 后 nZVI 颗粒中不同元素的空间分布(图 3e).nZVI 吸附、 还原 $\mathrm{U}(\mathrm{VI})$ 的性能受到溶液中 $\mathrm{U}(\mathrm{VI})$ 浓度 ${ }^{[50,95] 、 n Z V I}$ 浓 度、 $\mathrm{pH}^{[48,50,71,73,95] \text { 、溶解氧 }}[$ [73]、阳离子 $[50,71,77,96]$ 、阴离

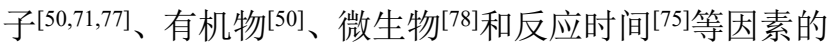
影响. 如 nZVI 在去离子水或碳酸氢钠溶液中氧化后的 产物分别为 $\gamma-\mathrm{FeOOH}$ 和 $\mathrm{Fe}_{3} \mathrm{O}_{4} / \gamma-\mathrm{Fe}_{2} \mathrm{O}_{3}$, 且其去除铀的机 理分别为沉淀或吸附/还原(图 3d). 应用 nZVI 处理铀尾 矿库浸渍水时，水溶液中多种共存离子影响 nZVI 去除 $\mathrm{U}(\mathrm{VI})$ 的性能，反应后颗粒中 $\mathrm{U}$ 的含量可达 $0.68 \%(w)$ 且 从颗粒表面至内部逐渐增加(图 3e). (a)

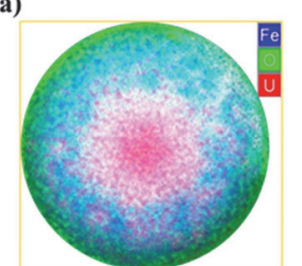

(c)

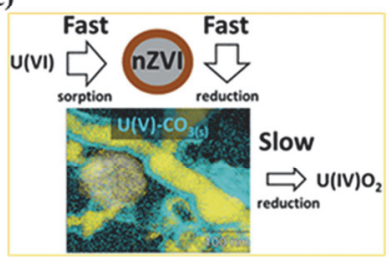

(e)

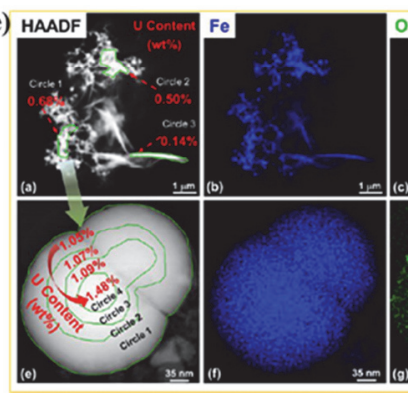

(b)

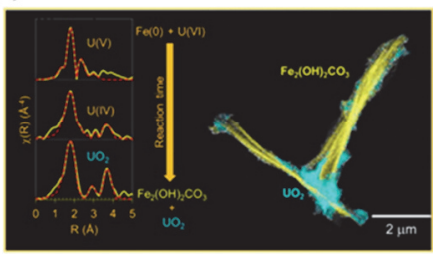

(d)
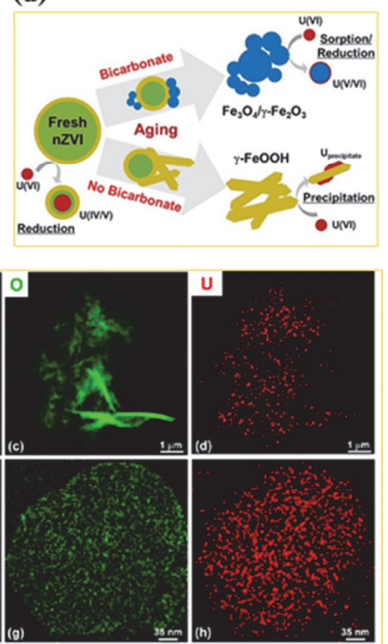

图 3 铀元素在反应后的 nZVI 颗粒中的空间分布 $(a, e)^{[49,51]}$ 及结构特 征 $(b)^{[87]}$, 以及 $\mathrm{HCO}_{3}{ }^{-}$对 $\mathrm{nZVI}$ 与铀反应过程的影响 $(\mathrm{c}, \mathrm{d})^{[41,72]}$

Figure 3 Spatial distribution $(\mathrm{a}, \mathrm{e})^{[49,51]}$ and forms $(\mathrm{b})^{[87]}$ of uranium in a reacted nZVI, and effect of bicarbonate on the reactions between uranium and $\mathrm{nZVI}(\mathrm{c}, \mathrm{d})^{[41,72]}$ 
$n Z V I$ 分离溶液中 $\mathrm{U}(\mathrm{VI})$ 的主要缺点包括以下三个 方面. 第一, 水溶液中 nZVI 颗粒的磁性及表面的静电 引力引起颗粒团聚而导致反应活性降低. 第二, 水中共 存组分与 $\mathrm{U}(\mathrm{VI})$ 配位或占据颗粒表面吸附/还原位点, 降 低 nZVI 吸附或还原 $\mathrm{U}(\mathrm{VI})$ 的性能. 第三, 废水中电子受 体(如 $\mathrm{H}^{+} 、 \mathrm{NO}_{3}{ }^{-} 、 \mathrm{SO}_{4}{ }^{2-}$ 、高价态重金属)和水分子与 $\mathrm{U}(\mathrm{VI})$
竞争 $\mathrm{Fe}(\mathrm{II})$ 或 $\mathrm{Fe}(0)$ 提供的电子，降低 $\mathrm{U}(\mathrm{VI})$ 被还原的速 率或程度. 为增强 nZVI 在复杂铀废水中的反应活性, 部分学者将 nZVI 负载于支撑材料或使用硫化等方式改 性 nZVI 可降低其团聚性能及电子传递选择性而提高分 离/还原 $\mathrm{U}(\mathrm{VI})$ 的速率和负荷(表 1) ${ }^{[34,48,50,95,97]}$.

表 $1 \mathrm{nZVI}$ 与铀反应的研究进展

Table 1 Research progress for the reactions between nZVI and uranium ions

\begin{tabular}{|c|c|c|c|c|}
\hline 材料 & 铀溶液 & 研究内容 & 主要结论 & 文献 \\
\hline \multirow[t]{7}{*}{ nZVI } & 自配水 & $\begin{array}{l}\text { 厌氧条件下, nZVI 富集水溶液中低浓度 } \\
\text { 铀的溶液化学反应特性, 并从原子尺度 } \\
\text { 分析了固相反应机理. }\end{array}$ & $\begin{array}{l}\text { (1) 铀富集在 nZVI 颗粒核心; } \\
\text { (2) 还原作用是主要反应机理; } \\
\text { (3) 铀去除负荷达到 } 1410 \mathrm{mg} / \mathrm{g} .\end{array}$ & [49] \\
\hline & 自配水 & $\begin{array}{l}\text { 厌氧条件下, } \mathrm{pH、} \text { 碳酸氢根、钲离子对 } \\
\mathrm{nZVI} \text { 分离、还原溶液中铀的影响. }\end{array}$ & $\begin{array}{l}\text { (1) 碳酸氢根、钲离子抑制 } \mathrm{nZVI} \text { 分离、还原铀; } \\
\text { (2) 铀被还原为 } \mathrm{UO}_{2} \text {; } \\
\text { (3) nZVI 被氧化为 } \mathrm{FeOOH} \text { 或 } \mathrm{Fe}_{2} \mathrm{O}_{3} \text {. }\end{array}$ & [71] \\
\hline & 自配水 & $\begin{array}{l}\text { 厌氧条件下, U/Fe 物质的量比对 nZVI 颗 } \\
\text { 粒中铀、铁化合物结构演变规律的影响. }\end{array}$ & $\begin{array}{l}\text { (1) 反应后 nZVI 颗粒中铀的价态包括 IV、V 和 IV; } \\
\text { (2) nZVI 转变为 } \mathrm{Fe}_{2}(\mathrm{OH})_{2} \mathrm{CO}_{3} \text {. }\end{array}$ & [87] \\
\hline & 自配水 & 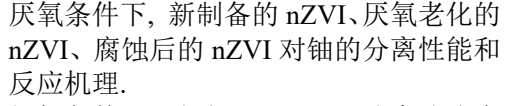 & $\begin{array}{l}\text { (1) nZVI 与铀反应的步骤是先吸附再还原; } \\
\text { (2) 厌氧老化的 nZVI 对铀的分离速率最快; } \\
\text { (3) 铀被还原并形成 } \mathrm{UO}_{2} \text {. }\end{array}$ & {$[72]$} \\
\hline & 自配水 & $\begin{array}{l}\text { 好氧条件下，溶液 pH对 nZVI 分离溶液中 } \\
\text { 高浓度铀的性能和反应机理. }\end{array}$ & $\begin{array}{l}\text { (1) nZVI 与铀的主要反应机理是还原作用; } \\
\text { (2) 铀被分离的速率随着 } \mathrm{pH} \text { 升高而加快; } \\
\text { (3) 溶液 } \mathrm{pH} \geqslant 5 \text { 时, 铀水解形成沉淀 } \mathrm{UO}_{3} \cdot 2 \mathrm{H}_{2} \mathrm{O} \text {. }\end{array}$ & [73] \\
\hline & 自配水 & $\begin{array}{l}\text { 厌氧条件下, Fe(II)或 Fe(III)对 nZVI 还原 } \\
\text { 铀的影响. }\end{array}$ & $\begin{array}{l}\text { (1) 1,10-邻菲罗啉或三乙醇胺不利于铀被还原; } \\
\text { (2) nZVI 表面的 Fe(II)促进铀被还原的过程. }\end{array}$ & [96] \\
\hline & $\begin{array}{l}\text { 自配水 / } \\
\text { 含铀废水 }\end{array}$ & $\begin{array}{l}\text { 好氧条件下, 钻离子、钠离子、碳酸氢根 } \\
\text { 对 nZVI 分离自配水、实际废水中低浓度 } \\
\text { 铀的影响. }\end{array}$ & $\begin{array}{l}\text { (1) } 0.5 \mathrm{~h} \text { 内, 钲离子、钠离子、碳酸氢根对 nZVI 去除铀的反 } \\
\text { 应速率无明显影响; } \\
\text { (2) 钙离子、碳酸氢根共存时, 颗粒中的铀易脱附. }\end{array}$ & [77] \\
\hline $\mathrm{nZVI} / \mathrm{C}$ & 自配水 & $\begin{array}{l}\text { 以 } \mathrm{Fe}_{2} \mathrm{O}_{3} \text { 和松木屑合成 } \mathrm{nZVI} / \mathrm{C} \text {, 研究其分 } \\
\text { 离铀的性能和机理. }\end{array}$ & $\begin{array}{l}\text { (1) 主要反应机理包括还原、吸附; } \\
\text { (2) nZVI/C 富集铀的负荷为 } 186.92 \mathrm{mg} / \mathrm{g} \text {. }\end{array}$ & [43] \\
\hline $\mathrm{nZVI} / \mathrm{AC}$ & 自配水 & $\begin{array}{l}\text { 以 } \mathrm{nZVI} \text { 和 } \mathrm{AC} \text { 制备 nZVI/AC, 并研究其 } \\
\text { 分离铀的溶液化学及固液界面机理. }\end{array}$ & $\begin{array}{l}\text { (1) } \mathrm{nZVI} / \mathrm{AC} \text { 主要通过吸附作用去除铀; } \\
\text { (2) } \mathrm{nZVI} / \mathrm{AC} \text { 富集铀的负荷为 } 138.88 \mathrm{mg} / \mathrm{g} \text {; } \\
\text { (3) 反应时间延长, 反应后 } \mathrm{nZVI} / \mathrm{AC} \text { 中铁氧化物由 } \mathrm{Fe}_{3} \mathrm{O}_{4} \text { 转变 } \\
\text { 为 } \mathrm{g}-\mathrm{FeOOH.}\end{array}$ & [34] \\
\hline $\mathrm{nZVI} / \mathrm{MC}$ & 自配水 & 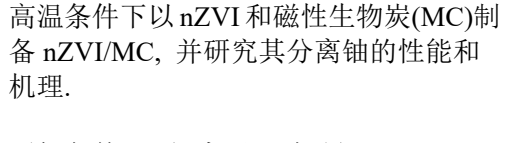 & $\begin{array}{l}\text { (1) } 800{ }^{\circ} \mathrm{C} \text { 条件提高复合材料中 nZVI 的分散、抗氧化性能; } \\
\text { (2) nZVI/MC 通过吸附、还原作用去除铀; } \\
\text { (3) } \mathrm{nZVI/MC} \text { 富集铀的负荷为 } 203.94 \mathrm{mg} / \mathrm{g} \text {; } \\
\text { (4) } \mathrm{nZVI} / \mathrm{MC} \text { 重复性能强, 最适 } \mathrm{pH} \text { 为 } 5 \sim 6 \text {. }\end{array}$ & [37] \\
\hline $\begin{array}{l}\text { nZVI/ } \\
\text { 红土 }\end{array}$ & 自配水 & $\begin{array}{l}\text { 厌氧条件下, 钲离子、碳酸根对 nZVI 及 } \\
\text { 红土分离溶液中铀的影响. }\end{array}$ & $\begin{array}{l}\text { (1) nZVI 去除铀的机理包括吸附、还原作用; } \\
\text { (2) nZVI 对铀的去除能力比红土强; } \\
\text { (3) nZVI 和红土对铀的分离性能随着 } \mathrm{pH} \text { 升高、碳酸根和钲离 } \\
\text { 子浓度的增加而降低. }\end{array}$ & [48] \\
\hline $\begin{array}{l}\mathrm{nZVI} / \text { 膨 } \\
\text { 润土 }\end{array}$ & 自配水 & $\begin{array}{l}\text { 厌氧条件下, nZVI/膨润土复合材料对铀 } \\
\text { 的分离性能及反应机理. }\end{array}$ & $\begin{array}{l}\text { (1) nZVI/膨润土将铀还原为 } \mathrm{UO}_{2} \text {; } \\
\text { (2) 膨润土可捕获铀、提供活性位点、缓冲 } \mathrm{pH} \text { 、分散 nZVI } \\
\text { 颗粒、吸附 } \mathrm{Fe}(\mathrm{II}) \text { 而促进还原铀. }\end{array}$ & [94] \\
\hline $\begin{array}{l}\mathrm{nZVI} / \text { 石 } \\
\text { 墨烯 }\end{array}$ & 自配水 & $\begin{array}{l}\text { 厌氧条件下, nZVI/石墨烯复合材料对铀 } \\
\text { 的分离性能及反应机理. }\end{array}$ & $\begin{array}{l}\text { (1) 石墨烯提高了去除铀的速率和负荷; } \\
\text { (2) 石墨烯抑制 } \mathrm{Fe}_{3} \mathrm{O}_{4} / \gamma-\mathrm{Fe}_{2} \mathrm{O}_{3} \text { 向 } \gamma-\mathrm{FeOOH} \text { 转变; } \\
\text { (3) 铀在复合材料表面形成 “内层”配合物. }\end{array}$ & [95] \\
\hline $\begin{array}{l}\mathrm{nZVI} / \\
\mathrm{LDH}\end{array}$ & 自配水 & & 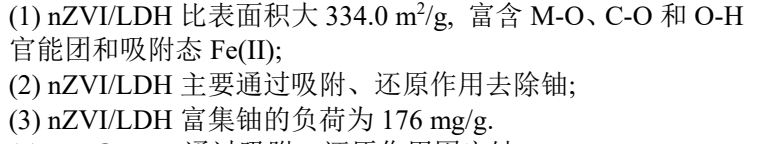 & [33] \\
\hline SnZVI & 自配水 & $\begin{array}{l}\text { 厌氧条件下, 以 } \mathrm{Na}_{2} \mathrm{~S} \text { 为硫化剂制备 } \\
\mathrm{FeS} @ \mathrm{nZVI} \text { 并研究其富集铀的机理. }\end{array}$ & $\begin{array}{l}\text { (1) FeS@nZVI 通过吸附、还原作用固定铀; } \\
\text { (2) FeS 和 nZVI 的最佳质量比为 } 1: 1 \text {; } \\
\text { (3) 溶液 pH(5.5 9.0)增加, FeS@nZVI 分离铀的性能升高; } \\
\text { (4) 腐殖酸、碳酸氢根和钲离子的抑制作用较弱. }\end{array}$ & [39] \\
\hline SnZVI/BC & 自配水 & 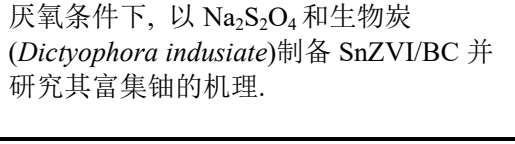 & $\begin{array}{l}\text { (1) SnZVI/BC 提高 nZVI 颗粒的分散性和抗氧化性; } \\
\text { (2) SnZVI/BC 表面的官能团(如 O-H、C-O、C-H、C-C、C = } \\
\text { C)和 FeSx 壳层通过吸附作用、还原作用去除铀; } \\
\text { (3) SnZVI/BC 循环性能强, 且富集铀的负荷为 } 427.9 \mathrm{mg} / \mathrm{g} \text {. }\end{array}$ & [36] \\
\hline
\end{tabular}

Layered Double Hydroxide; SnZVI 为硫化纳米零价铁, 即 Sulfidated nanoscale Zero-valent iron. 


\subsection{2 nZVI 复合材料}

为提高 nZVI 颗粒在地下水中的迁移能力和反应活 性, 研究人员将 nZVI 负载于多种材料(如石墨烯、蒙脱 石、硅藻土、膨润土、活性炭、伊利石、红土、污泥、 金属有机骨架和层状双氢氧化物) 以制备 nZVI复合材料 (图 4) ${ }^{[33,46,81-83,91,93-95,97]}$. nZVI 复合材料中 nZVI 颗粒的分 散性和迁移性明显增强, 其去除 U(VI) 的负荷由 2.4 $\mathrm{g} / \mathrm{g}(\mathrm{nZVI})^{[49]}$ 增高至 $8.2 \mathrm{~g} / \mathrm{g}(\mathrm{nZVI}-\text { 石墨烯 })^{[50]}$, 反应速率 由 $0.005 \mathrm{~min}^{-1}(\mathrm{nZVI})$ 提高至 $0.021 \mathrm{~min}^{-1}$ (nZVI-硅藻土) 或 $0.017 \mathrm{~min}^{-1}(\mathrm{nZVI}$-蒙脱石), 并且反应后的颗粒表面 $(\approx 10 \mathrm{~nm})$ 中 $\mathrm{U}(\mathrm{IV})$ 的含量由 $33 \%$ 提高至 $67 \%{ }^{[47,85]}$. 支撑 材料主要通过以下四种途径提高 U(VI)去除的性能: (1) 将 nZVI 颗粒均匀分布在材料表面, 降低 nZVI 颗粒团聚 沉降程度 ${ }^{[42,50]}$; (2)提供含氧官能团(如 $\mathrm{O}-\mathrm{H} 、 \mathrm{COOH}$ )以增 强吸附 $\mathrm{U}(\mathrm{VI})^{[50]}$; (3) 捕获溶液中的 $\mathrm{Fe}(\mathrm{II})$, 提高材料对 $\mathrm{U}(\mathrm{VI})$ 的还原作用 ${ }^{[47,85]}$; (4)降低水质因素(如 $\mathrm{pH}$ 、碳酸根、 腐殖酸)的抑制作用 ${ }^{[50,85]}$.

针对 nZVI 向 U(VI) 传递电子效率低的问题, 研究人 员利用硫化剂改性 nZVI 颗粒表面制备 SnZVI 以提高 $n Z V I$ 颗粒中 Fe 向 U(VI)传递电子的选择性 ${ }^{[98-102]}$. SnZVI 壳层主要物质为强疏水性的硫铁化合物 $\left(\mathrm{FeS}_{x}\right)$, 其可降 低 $\mathrm{Fe}$ 与 $\mathrm{H}_{2} \mathrm{O}$ 间的氧化还原反应 ${ }^{[103]}$, 提高颗粒中电子供 体(如 $\mathrm{Fe}^{0} 、 \mathrm{Fe}^{2^{+}} 、 \mathrm{~S}^{2-}$ ) 向污染物质(如 $\mathrm{U}^{[36,39]} 、 \mathrm{Cr}^{[104]} 、 \mathrm{Sb}^{[105]}$ 和 $\mathrm{TCE}^{[106]}$ )传递电子的效率. $\mathrm{Xu}$ 等 ${ }^{[98-99]}$ 的研究结果表明, SnZVI 向三氯乙烯 (TCE) 传递电子的效率达到 240

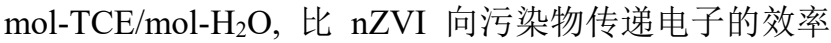
提高 160 倍. Duan 等[39]以“两步法”制备的 FeS@Fe (1/1, $\mathrm{mol} / \mathrm{mol}$ )颗粒可在更长时间内保持还原性, 且铁、硫通 过还原作用固定溶液中的 $\mathrm{U}(\mathrm{VI})$, 其对 $\mathrm{U}(\mathrm{VI})$ 的去除速 率为 nZVI 的 1.31 倍. 将 SnZVI 负载于生物炭上, 可进 一步提高电子供体向 U(VI)传递电子的效率及还原态铀 在氧化性条件中的抗氧化性, 且将 U(VI)的去除负荷提 高 $20 \%{ }^{[36]}$. 上述研究表明硫化改性的方式能够提高 $n Z V I$ 去除简单水溶液中 U(VI)的性能. 但是, SnZVI 能 否在复杂含铀废水保持良好的物理化学反应活性及电 子传递选择性, 以及 SnZVI 颗粒中铀的长期稳定性等问 题仍需进行大量实验、理论数据进行分析.

\section{$3 \mathrm{nZVI}$ 分离铀的机理及影响因素}

nZVI 主要通过液相、固-液界面和固相反应过程富 集水溶液中的铀. 首先液相中的 U(VI)与共存离子形成 稳定的配合物, 然后配合离子扩散通过液膜并在静电作 用/表面配位作用下被吸附至 nZVI 表面，最后通过还原 作用被固定在 nZVI 颗粒中. 在此过程中, U(VI)也可与 水溶液中的阴离子/阳离子形成沉淀而附着在 nZVI 颗粒 表面(图 4e). 因此, nZVI 去除水溶液中铀的机理主要包 括吸附/解吸、还原和沉淀等作用，且该过程受到 nZVI 颗粒结构及水质条件的影响. 本部分将重点探讨 nZVI 分离铀的机理, 以及水质因素条件对铀分离过程的影响 程度及原因。 (a)

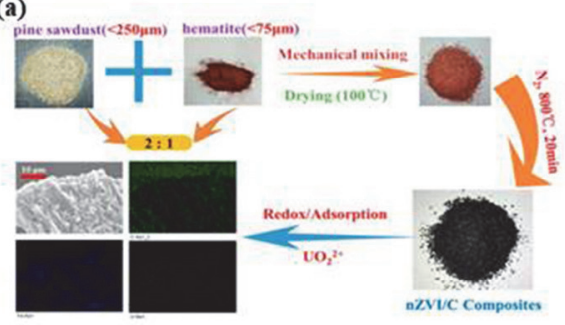

(b)

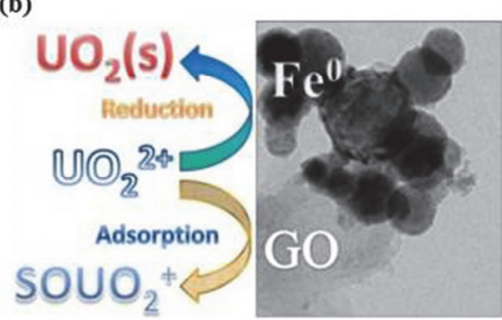

(c)

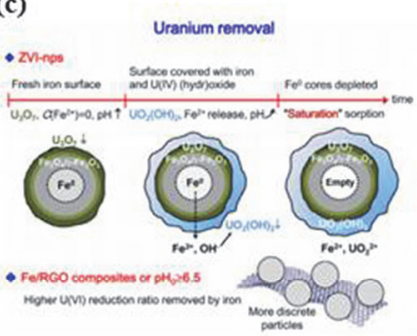

(d)

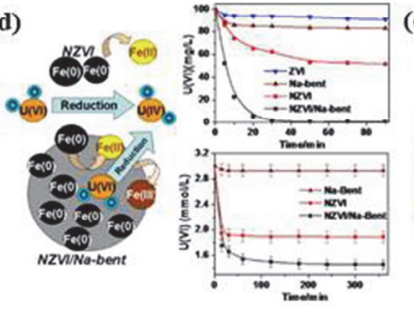

(g)

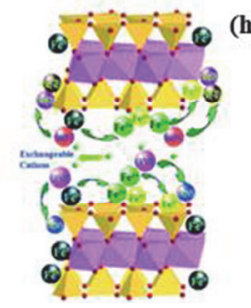

(h)

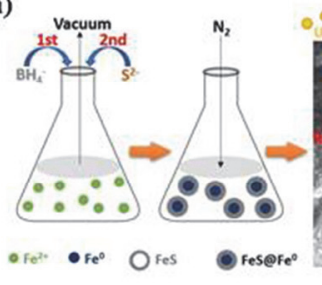

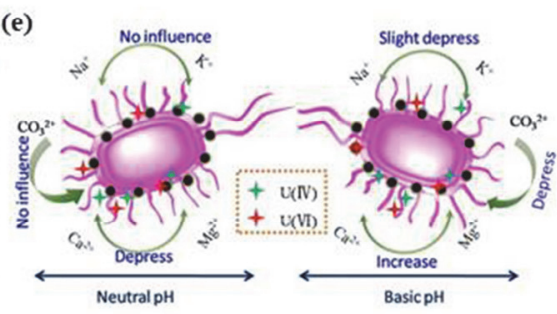

(i)

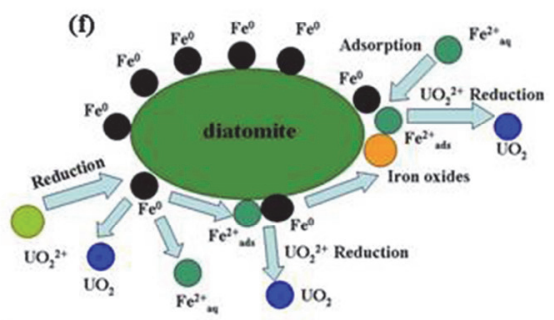

(i)

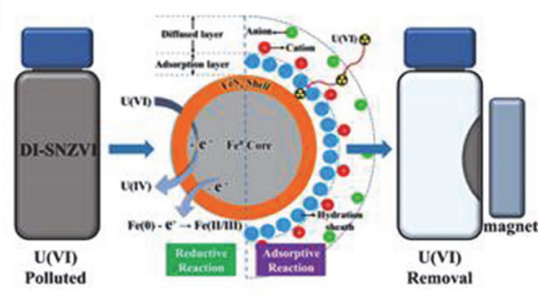

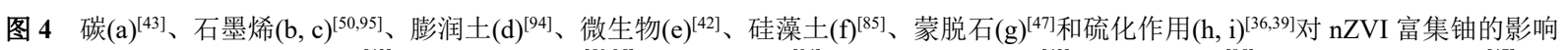

Figure 4 Effects of carbon $(\mathrm{a})^{[43]}$, grapheme $(\mathrm{b}, \mathrm{c})^{[50,95]}$, bentonite $(\mathrm{d})^{[94]}$, microorganism $(\mathrm{e})^{[42]}$, diatomite $(\mathrm{f})^{[85]}$, mentmorillonite $(\mathrm{g})^{[47]}$ and sulfidization $(h, \mathrm{i})^{[36,39]}$ on uranium enrichment by nZVI 


\section{1 反应机理}

\section{1 .1 吸附作用}

nZVI 吸附水溶液中的铀, 主要由表面官能团通过 静电引力、范德华力以及质子交换等作用吸附 $U(V I)$, 并以 “内层” 或 “外层” 配合物的形式将铀固定在颗粒

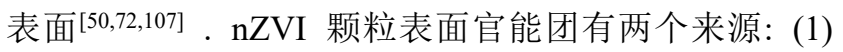
nZVI 或 SnZVI 颗粒壳层的铁氧化物、硫铁化合物表面 在水溶液中(去)质子化过程产生的带电活性位点(如羟 基) ${ }^{[36]}$; (2)复合 nZVI 颗粒中支撑材料(如羧甲基纤维素、 还原石墨烯、枯草芽孢杆菌、藻酸钙等)的表面固有的 官能团(如羟基、羧基、磷酸基) ${ }^{[43-44,78,85,91,95,108-112]}$. 虽然 $\mathrm{nZVI}$ 吸附水溶液中 U(VI)的速率快、选择性强、负荷高. 但是, 实际铀废水的水质组分可与铀离子形成多种形态 配合物或改变颗粒表面化学性质, 降低 nZVI 吸附水溶 液中铀的性能.

\section{1 .2 还原作用}

将 $\mathrm{U}(\mathrm{VI})$ 还原为 $\mathrm{U}(\mathrm{V}) / \mathrm{U}(\mathrm{IV})$ 是 $n Z V I$ 去除溶液中铀 的重要机理 ${ }^{[73]}$. nZVI 还原铀的电子供体包括核心的单 质铁 $\left(\mathrm{Fe}^{0}\right.$ )、壳层铁氧化物(如 $\mathrm{Fe}_{3} \mathrm{O}_{4}, \mathrm{Fe}_{2} \mathrm{O}_{3}, \mathrm{FeOOH}$ ) 晶体 及表面吸附的 $\mathrm{Fe}(\mathrm{II})($ 式 $1 \sim 4)$ 和溶液中的 $\mathrm{Fe}(\mathrm{II})$ 离 子 ${ }^{[94,96]}$. nZVI 颗粒中, 电子供体向 U(VI)传递电子的途 径包括: (1)电子供体直接传递电子至 U(VI); (2)电子通 过颗粒的表面缺陷(如空穴、晶界)进行传递; (3)壳层铁 氧化物中 $\mathrm{Fe}(\mathrm{II}) / \mathrm{Fe}(\mathrm{III})$ 电对的氧化还原过程. 热力学计 算结果表明, 溶液中的 Fe(II)离子也可还原 U(VI), 但是 不同学者的实验结论并不一致 ${ }^{[72-73,78,94,96,113]}$. U(VI)接受 电子后主要通过两种方式被还原: (1) U(VI)获得两个电 子后先被还原为 $U(V)$, 然后被进一步还原为 U(IV); (2) $\mathrm{U}(\mathrm{VI})$ 获得电子并直接被还原为 $U(I V)^{[72]}$. U(VI)被还原 后的产物包括 $\mathrm{UO}_{2}(\mathrm{~s})$ 和 $\mathrm{U}_{3} \mathrm{O}_{7}$ 等 $[43,50,73,87]$. 部分学者提出 铁基纳米材料 (如 $\mathrm{FeS}^{[114]} 、 \mathrm{Fe}_{5} \mathrm{HO}_{8} \bullet 4 \mathrm{H}_{2} \mathrm{O}^{[115-116]}$ 、 $\left.\mathrm{Fe}_{3} \mathrm{O}_{4}{ }^{[117-118]}\right)$ 还原 $\mathrm{U}(\mathrm{VI})$ 的过程中, $\mathrm{U}(\mathrm{IV})$ 来自于 $\mathrm{U}(\mathrm{V})$ 的 歧化反应. 在 $n Z V I-U(V I)$ 反应体系中, $\mathrm{Fe}$ 可转化为 $\mathrm{FeS}$ 、 $\mathrm{Fe}_{5} \mathrm{HO}_{8} \bullet 4 \mathrm{H}_{2} \mathrm{O}$ 和 $\mathrm{Fe}_{3} \mathrm{O}_{4}$ 等铁氧化物. 但是, U(V)的歧化反 应对 nZVI 去除 U(VI) 的影响尚未得到详尽的验证. 含铀 废水中的水质组分 (如 $\mathrm{HCO}_{3}{ }^{-} 、 \mathrm{NO}_{3}{ }^{-} 、 \mathrm{O}_{2} 、 \mathrm{Fe}(\mathrm{III})$ ) 可消 耗 nZVI 中的还原组分 $(\mathrm{Fe}(0)$ 和 $\mathrm{Fe}(\mathrm{II}))$, 或者与 U(VI)形 成配合物后改变 $U(V I) / U(I V)$ 的氧化还原电势而影响 $n Z V I$ 还原 U(VI)的效率[119-120].

$$
\begin{aligned}
& \mathrm{UO}_{2}{ }^{++}+\mathrm{Fe} \rightarrow \mathrm{UO}_{2}+\mathrm{Fe}^{2+} \\
& \mathrm{UO}_{2}{ }^{2+}+2 \mathrm{Fe}^{2+} \rightarrow \mathrm{UO}_{2}+2 \mathrm{Fe}^{3+} \\
& 3 \mathrm{UO}_{2}{ }^{2+}+2 \mathrm{Fe} \rightarrow 3 \mathrm{UO}_{2}+2 \mathrm{Fe}^{3+} \\
& 2 \mathrm{Fe}^{3+}+\mathrm{Fe} \rightarrow 3 \mathrm{Fe}^{2+}
\end{aligned}
$$

\subsection{3 沉淀作用}

水溶液中 $\mathrm{U}(\mathrm{VI})$ 可在近中性及碱性条件下与多种阴 离子/阳离子形成沉淀(式 5 10). MEDUSA 软件计算结 果表明, U(VI) 与氢氧根形成 $\mathrm{UO}_{2}(\mathrm{OH})_{2} \bullet \mathrm{H}_{2} \mathrm{O}$ 和
$\mathrm{UO}_{3} \cdot 2 \mathrm{H}_{2} \mathrm{O}$ 等氢氧化物型沉淀, $\mathrm{CO}_{3}{ }^{2-}$ 和 $\mathrm{PO}_{4}{ }^{3-}$ 可提高铀 水溶液中的 $\mathrm{U}(\mathrm{VI})$ 溶解度. 但是, 当溶液中存在 $\mathrm{Ca}$ 离子 时, U(VI)在中性至碱性条件下形成沉淀的趋势明显增 强, 而 $\mathrm{CO}_{3}{ }^{2-}$ 和 $\mathrm{PO}_{4}{ }^{3-}$ 可提高铀在 U-Ca-O-H 体系中的溶 解度(图 5). 众多科研团队的实验结果同样证明 U(VI)可 与 $\mathrm{PO}_{4}{ }^{3-}, \mathrm{Na}^{+}, \mathrm{Ca}^{2+}$ 等形成沉淀(如 $\mathrm{UO}_{2}(\mathrm{OH})_{2} \cdot \mathrm{H}_{2} \mathrm{O}$ 、 $\mathrm{UO}_{3} \bullet 2 \mathrm{H}_{2} \mathrm{O} 、 \mathrm{UO}_{2} \mathrm{HPO}_{4} \bullet 4 \mathrm{H}_{2} \mathrm{O} 、 \mathrm{Na}_{2}\left(\mathrm{UO}_{2} \mathrm{PO}_{4}\right)_{2} \bullet x \mathrm{H}_{2} \mathrm{O}$ 和 $\left.\mathrm{Ca}\left(\mathrm{UO}_{2}\right)_{2}\left(\mathrm{PO}_{4}\right)_{2}\right)$ 而改变 $n Z V I$ 去除 $\mathrm{U}(\mathrm{VI})$ 的性能 ${ }^{[12,121-126]}$. 但是, 尚未有详实的数据评估沉淀过程对 nZVI 去除溶 液中 $\mathrm{U}(\mathrm{VI})$ 离子动力学过程的影响. 简单水质条件下, $n Z V I$ 富集 $\mathrm{U}(\mathrm{VI})$ 的反应在数分钟内达到平衡. 而 Riba 等 ${ }^{[73]}$ 的实验结果表明, U(VI)(849.66 mg/L)在 $\mathrm{pH} 3.0$ 7.0 的条件下稳定 $4 \mathrm{~h}$ 或 $7 \mathrm{~d}$ 后仅有少于 $6.6 \%$ 或 $32 \%$ 的 $\mathrm{U}(\mathrm{VI})$ 形成沉淀 $\left(\mathrm{UO}_{3} \cdot 2 \mathrm{H}_{2} \mathrm{O}\right)$. 因此, 沉淀作用是否为 $\mathrm{nZVI}$ 去除溶液中铀的重要反应机理仍需结合实际废水 性质及实验条件而进行判定.

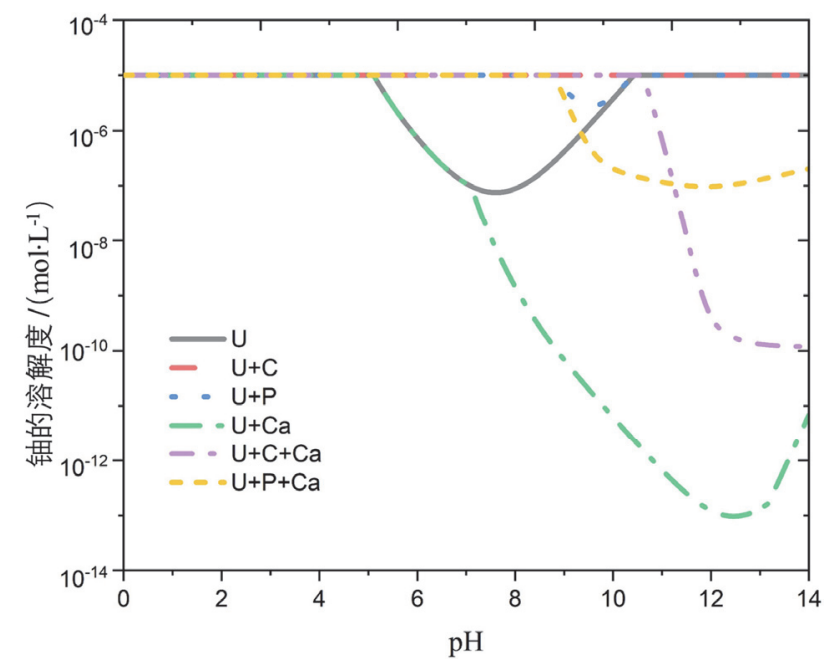

图 $525{ }^{\circ} \mathrm{C}$ 溶液 $\mathrm{pH}$ 和共存离子对铀溶解度的影响. ([U] 总 $=0.01$ $\left.\mathrm{mmol} / \mathrm{L},[\mathrm{C}]_{\text {总 }}=1 \mathrm{mmol} / \mathrm{L},[\mathrm{P}]_{\text {总 }}=10 \mathrm{mmol} / \mathrm{L},[\mathrm{Ca}]_{\text {总 }}=1 \mathrm{mmol} / \mathrm{L}\right)$ Figure 5 Solubility of uranium under different solution $\mathrm{pH}$ and co-existed ions conditions at $25{ }^{\circ} \mathrm{C} .\left([\mathrm{U}]_{\text {total }}=0.01 \mathrm{mmol} / \mathrm{L},[\mathrm{C}]_{\text {total }}=1\right.$ $\left.\mathrm{mmol} / \mathrm{L},[\mathrm{P}]_{\text {total }}=10 \mathrm{mmol} / \mathrm{L},[\mathrm{Ca}]_{\text {total }}=1 \mathrm{mmol} / \mathrm{L}\right)$

$$
\begin{gathered}
\mathrm{UO}_{2}{ }^{2+}+2 \mathrm{OH}^{-}=\mathrm{UO}_{2}(\mathrm{OH})_{2} \cdot 2 \mathrm{H}_{2} \mathrm{O} \log k=-4.81 \\
\mathrm{UO}_{2}{ }^{2+}+\mathrm{CO}_{3}{ }^{2-}=\mathrm{CaCO}_{3} \quad \log k=14.47 \\
3 \mathrm{UO}_{2}{ }^{2+}+\mathrm{Ca}^{2+}=\mathrm{CaUO}_{4} \quad \log k=-16.03 \\
3 \mathrm{UO}_{2}{ }^{2+}+2 \mathrm{PO}_{4}{ }^{3-}=\left(\mathrm{UO}_{2}\right)_{3}\left(\mathrm{PO}_{4}\right)_{2} \quad \log k=36.34 \\
2 \mathrm{H}^{+}+2 \mathrm{UO}_{2}{ }^{2+}+2 \mathrm{PO}_{4}{ }^{3-}=\left(\mathrm{UO}_{2}\right)_{2} \mathrm{P}_{2} \mathrm{O}_{7} \quad \log k=36.99 \\
\mathrm{H}^{+}+\mathrm{UO}_{2}{ }^{2+}+\mathrm{PO}_{4}{ }^{3-}=\mathrm{UO}_{2} \mathrm{HPO}_{4} \bullet 4 \mathrm{H}_{2} \mathrm{O} \log k=24.20
\end{gathered}
$$

\section{1 .4 其它作用}

实验及理论计算结果表明, U(VI)与铁氧化物反应 的过程中 U(VI)可进入铁氧化物的晶体(图 6 ${ }^{[108,127-129]}$. 如水铁矿 $\left(\mathrm{Fe}(\mathrm{OH})_{3}\right)$ 转变为针铁矿 $(\alpha-\mathrm{FeOOH})$ 和磁铁矿 $\left(\mathrm{Fe}_{3} \mathrm{O}_{4}\right)$ 的过程中, $\mathrm{U}(\mathrm{VI})$ 和 $\mathrm{U}(\mathrm{V})$ 可进入针铁矿、纤铁矿 $(\gamma-\mathrm{FeOOH})$ 和磁铁矿晶体并替换 $\mathrm{Fe}(\mathrm{III})$ 离子[129-130]. 
(a)

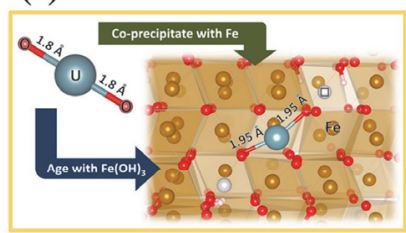

(c)

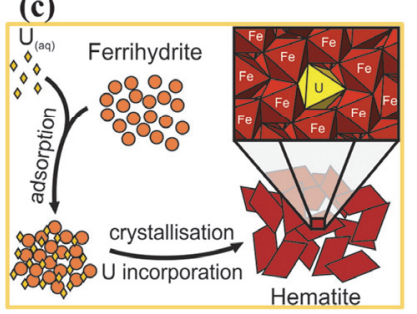

(b)

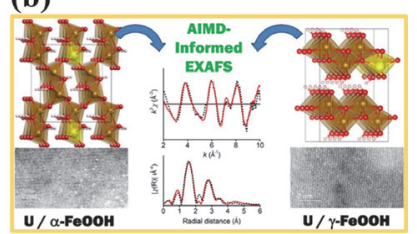

(d)

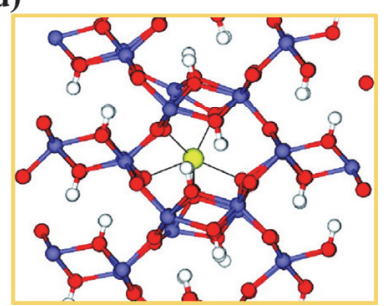

图 6 铀替换铁氧化物晶体中铁原子的机理 ${ }^{[108,128-130]}$

Figure 6 Mechanisms for uranium to replace iron in iron oxides $^{[108,128-130]}$

水溶液中, nZVI 颗粒被氧化为多种铁氧化物(如 $\left.\mathrm{Fe}(\mathrm{OH})_{3} 、 \mathrm{Fe}_{3} \mathrm{O}_{4} 、 \gamma-\mathrm{FeOOH} 、 \alpha-\mathrm{FeOOH}\right)^{[131-132]}$. 因此, $\mathrm{U}(\mathrm{VI})$ 与 $\mathrm{nZVI}$ 反应的过程中, $\mathrm{U}(\mathrm{VI})$ 也可替代 $\mathrm{nZVI}$ 壳层 铁氧化物晶体中的 $\mathrm{Fe}(\mathrm{III})$ 后生成 $\left(\mathrm{U}_{x} \mathrm{Fe}_{1-x}\right)(\mathrm{OH})_{3}$ 或者 $\mathrm{U}_{x} \mathrm{Fe}_{1-x} \mathrm{OOH}^{[93,133]}$. 若 $\mathrm{U}(\mathrm{VI})$ 替代铁氧化物晶体中的 $\mathrm{Fe}(\mathrm{III})$, 将明显提高固相产物中铀的稳定性 ${ }^{[134-135]}$. 因 此, U(VI) 是否能够替代 nZVI 氧化后铁氧化物中的 $\mathrm{Fe}(\mathrm{III})$, 以及相关动力学和热力学特征以及水质因素的 影响需进行深入的研究.

\section{2 影响因素}

铀矿石的酸法、碱法浸出过程使用的化学试剂及矿 石组分溶解阶段, 多种阳离子(如 $\mathrm{Ca} 、 \mathrm{Mg} 、 \mathrm{Na} 、 \mathrm{Fe}$ )、 阴离子 (如 $\mathrm{HCO}_{3}{ }^{-} 、 \mathrm{SO}_{4}{ }^{2-} 、 \mathrm{PO}_{4}{ }^{3-}$ ) 和有机物 ${ }^{[83,136-137]}$ 被引 入铀废水中(如地下水、铀尾矿浸渍水). 共存溶质可影 响溶液中铀离子的结构、nZVI/复合材料表面吸附铀的 官能团的性质、以及电子供体向 U(VI)传递电子的途径 和效率, 进而改变 nZVI 分离铀的效率(式 $11 \sim$

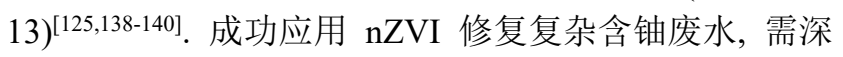
入分析各主要水质因素单独及协同影响 nZVI 吸附、还 原铀的过程的机理及程度.

$$
\begin{aligned}
& \mathrm{S}-\mathrm{OH}+\mathrm{L}^{-} \leftrightarrow \mathrm{S}-\mathrm{L}+\mathrm{OH}^{-} \\
& \mathrm{S}-\mathrm{OH}+\mathrm{L}^{-}+\mathrm{M}^{Z^{+}} \leftrightarrow \mathrm{S}-\mathrm{L}-\mathrm{M}^{Z^{+}}+\mathrm{OH}^{-} \\
& \mathrm{S}-\mathrm{OH}+\mathrm{L}^{-}+\mathrm{M}^{Z^{+}} \leftrightarrow \mathrm{S}-\mathrm{OM}-\mathrm{L}^{(Z-2)^{+}}+\mathrm{H}^{+}
\end{aligned}
$$

式中: $\mathrm{S}$ 为固体表面; $\mathrm{L}^{-}$为配位体; $\mathrm{M}^{\mathrm{Z}^{+}}$为 $\mathrm{U}(\mathrm{VI})$.

\subsection{1 $\mathrm{pH}$}

铀矿冶(硫酸浸出法、碳酸氢钠浸出法)过程产生的 含铀废水的 $\mathrm{pH}$ 呈现强酸性至强碱性 ${ }^{[141-143]} . \mathrm{pH}$ 可影响 溶液中 $\mathrm{U}(\mathrm{VI})$ 的形态及 nZVI 颗粒表面化学性质, 改变 $\mathrm{nZVI}$ 颗粒吸附或还原 $\mathrm{U}(\mathrm{VI})$ 的过程. 如在氧化性 $\left(E_{\mathrm{h}}>0\right)$ 溶液中, 随着 $\mathrm{pH}$ 的增加, $\mathrm{U}(\mathrm{VI})$ 离子与氢氧根配位后带 电性质由正电荷 (如 $\mathrm{UO}_{2}{ }^{2+},(\mathrm{UO})_{2}(\mathrm{OH})_{2}{ }^{2+}$ ) 变为电中性 (如 $\left.(\mathrm{UO})_{2}(\mathrm{OH})_{2}\right)$ 或负电荷 $\left(\right.$ 如 $\left(\mathrm{UO}_{2}(\mathrm{OH})_{3}{ }^{-}, \mathrm{UO}_{2}(\mathrm{OH})_{4}{ }^{2-}\right.$ ),

而当溶液的氧化性减弱后, 溶液 $\mathrm{pH}$ 主要影响 $\mathrm{U}(\mathrm{VI})$ 离子 的电子被还原的程度(如 $\mathrm{V}$ 或 IV)(图 7). 当溶液 $\mathrm{pH}$ 由酸 性变为碱性时, $\mathrm{nZVI}$ 及其复合材料 $\left(\mathrm{pH}_{\mathrm{zpc}}=5.0 \sim\right.$ $8.3)^{[17-18,52,78]}$ 的表面净电荷由正电荷变为负电荷. 因此, 不同 $\mathrm{pH}$ 条件下, $\mathrm{nZVI}$ 与 $\mathrm{U}(\mathrm{VI})$ 间的静电引力导致 $\mathrm{U}(\mathrm{VI})$ 被吸附的速率和负荷发生明显变化. 众多学者的研究结 果均表明, 溶液由酸性变为中性, nZVI 分离铀的速率增 快; 溶液由中性变为碱性, nZVI 分离铀的速率不变或降

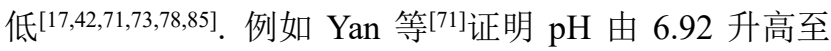
$9.03, n Z V I$ 去除铀的准一级速率常数从 $(28.8 \pm 3.5) \mathrm{h}^{-1}$ 降 低至 $(1.5 \pm 0.1) \mathrm{h}^{-1}$. 但是, 不同学者对溶液 $\mathrm{pH}$ 影响 nZVI 还原铀的结论存在差异. Yan 等 ${ }^{[71]}$ 的研究结果表明, $\mathrm{pH}$ 由 6.92 升高至 $9.03, \mathrm{nZVI}$ 还原铀的速率由 $(6.1 \pm 0.8)$ $\mathrm{h}^{-1}$ 降低至 $(0.92 \pm 0.15) \mathrm{h}^{-1}$. 而 Ding ${ }^{[42]} 、 \mathrm{Riba}^{[73]}$ 等的实验 结果证明碱性条件提高了 nZVI 还原铀的速率和负荷. Riba 等 ${ }^{[73]}$ 指出弱酸性条件下 nZVI 去除铀的机理包括水 解沉淀 $\left(\mathrm{UO}_{3} \cdot 2 \mathrm{H}_{2} \mathrm{O}\right)$ 和还原作用, 而碱性条件下 nZVI 对 铀的还原作用增强, 且无 $\mathrm{UO}_{3} \cdot 2 \mathrm{H}_{2} \mathrm{O}$ 生成. $\mathrm{Liu}$ 等 ${ }^{[43]}$ 以扩 展 X 射线吸收精细结构谱(EXAFS)分析反应后 nZVI 颗 粒中铀的结构形态，结果进一步表明酸性(pH 3.0)条件 下铀主要以 “内层” 配合物 $(\mathrm{U}(\mathrm{VI}))$ 的形式被吸附在 $\mathrm{nZVI} / \mathrm{C}$ 表面, 而 $\mathrm{pH}$ 为 9.0 时 $\mathrm{nZVI} / \mathrm{C}$ 表面 $\mathrm{UO}_{2}$ 的含量 显著增加.
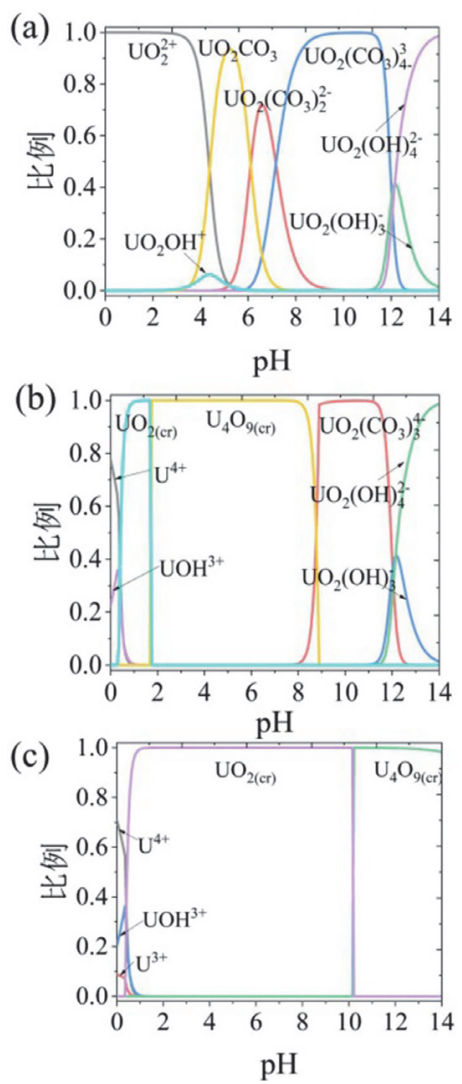

图 $725{ }^{\circ} \mathrm{C}$ 时, U-O-H 体系中不同 $\mathrm{pH}$ 条件下各主要形态 $\mathrm{U}$ 化合物的 比例. [U] $]^{\text {总 }}=0.001 \mathrm{mmol} / \mathrm{L}$, (a) $E_{\mathrm{h}}=0.5 \mathrm{~V}$, (b) $E_{\mathrm{h}}=0 \mathrm{~V}$, (c) $E_{\mathrm{h}}=-0.5 \mathrm{~V}$ Figure 7 Fraction of uranium under different $\mathrm{pH}$ in the U-O-H system at $25{ }^{\circ} \mathrm{C}$. [U $]_{\text {total }}=0.001 \mathrm{mmol} / \mathrm{L}$, (a) $E_{\mathrm{h}}=0.5 \mathrm{~V}$, (b) $E_{\mathrm{h}}=0 \mathrm{~V}$, (c) $E_{\mathrm{h}}=$ $-0.5 \mathrm{~V}$ 
综上所述, 溶液 $\mathrm{pH}$ 影响 $\mathrm{nZVI}$ 分离溶液中铀的原因 包括: (1) $\mathrm{pH}$ 升高, nZVI 颗粒表面与铀离子间的静电引 力减弱而导致铀被吸附的过程受到抑制; (2) 酸性条件 下，氢离子易于接受电子，抑制 $U(V I)$ 接受电子被还原 的程度 ${ }^{[42]} ;$ (3) 溶液由酸性变为碱性, nZVI 颗粒表面的 官能团由 $\equiv\left(\mathrm{Fe}^{\mathrm{III}} \mathrm{OFe} e^{\mathrm{II}}\right)^{+}$转变为 $\equiv\left(\mathrm{Fe}^{\mathrm{III}} \mathrm{OFe}{ }^{\mathrm{II}} \mathrm{OH}\right)^{0}$, 后者 还原铀(U(VI)) 的能力更强 ${ }^{[144]}$; (4) 溶液初始 $\mathrm{pH}$ 升高, $n Z V I$ 颗粒的溶解/沉淀腐蚀过程降低, 导致 nZVI 壳层中 $\mathrm{Fe}(\mathrm{II})$ 含量降低 ${ }^{[50,73,85,96]}$.

\subsection{2 阴离子}

铀矿石的酸法、碱法浸出过程使用的化学试剂及矿 石组分溶解后导致废水中存在多种阴离子(如 $\mathrm{HCO}_{3}^{-}$、 $\mathrm{SO}_{4}{ }^{2-}$ 、 $\mathrm{PO}_{4}{ }^{3-}$ 等). $\mathrm{HCO}_{3}{ }^{-}$和 $\mathrm{PO}_{4}{ }^{3-}$ 可与 $\mathrm{U}(\mathrm{VI})$ 形成多种带 电性质不同的配合物, 并可改变 U(VI)电子供体被还原 的程度(图 8). 同时, $\mathrm{HCO}_{3}{ }^{-}$和 $\mathrm{PO}_{4}{ }^{3-}$ 能够影响 nZVI 颗粒 的结构特征(表面电荷、铁氧化物种类等).

$\mathrm{HCO}_{3}{ }^{-}$主要影响 nZVI 吸附/还原铀的速率与负荷以 及 nZVI 反应产物的种类 $[41,48,71-72,77-78,85,87,145-147]$. 例如厌 氧条件下, 当溶液 $(\mathrm{pH}=6.92)$ 中 $\mathrm{CO}_{3}{ }^{2-}$ 浓度由 $0 \mathrm{mmol} / \mathrm{L}$ 增加至 $10 \mathrm{mmol} / \mathrm{L}$ 时, $\mathrm{nZVI}$ 分离 $\mathrm{U}(\mathrm{VI})$ 的速率常数从 $(28.8 \pm 3.5) \mathrm{h}^{-1}$ 降低至 $(0.029 \pm 0.004) \mathrm{h}^{-1}, \mathrm{U}(\mathrm{VI})$ 被还原的 速率从 $(6.1 \pm 0.8) \mathrm{h}^{-1}$ 降低至 $(0.029 \pm 0.003) \mathrm{h}^{-1[71]} . \mathrm{CO}_{3}{ }^{2-}$ 浓度由 $0 \mathrm{mmol} / \mathrm{L}$ 增加至 $4 \mathrm{mmol} / \mathrm{L}$ 时, nZVI 对 $\mathrm{U}(\mathrm{VI})$ 的 去除率由 $91.90 \%$ 降低至 $59.54 \%$, 固-液分配系数 $\left(K_{\mathrm{d}}\right)$ 由 $3.91 \times 10^{4} \mathrm{~mL} / \mathrm{g}$ 降低至 $1.14 \times 10^{3} \mathrm{~mL} / \mathrm{g}^{[48]}$. 反应后 $\mathrm{nZVI}$ 颗粒中铁、铀化合物的种类及元素空间分布特性同样受 到 $\mathrm{CO}_{3}{ }^{2-}$ 的影响. 如厌氧条件下, nZVI 中铁氧化物主要 为 $\mathrm{Fe}_{2}(\mathrm{OH})_{2} \mathrm{CO}_{3}$, 铀化合物包括 $\mathrm{UO}_{2(\mathrm{~s})}$ 和吸附态的铀配 合物 ${ }^{[87]}$; 好氧条件下, nZVI 在 0 或 $10 \mathrm{mmol} / \mathrm{L}$ 的 $\mathrm{CO}_{3}{ }^{2-}$ 溶液中被氧化为 $\gamma-\mathrm{FeOOH}$ 或 $\mathrm{Fe}_{3} \mathrm{O}_{4} / \gamma-\mathrm{Fe}_{2} \mathrm{O}_{3}{ }^{[41]}$. 对于 nZVI 颗粒, 铀富集在颗粒的核心区域 ${ }^{[41,49]}$; 而铀以块状 化学沉淀 $\left(\mathrm{UO}_{2.86} \bullet 1.5 \mathrm{H}_{2} \mathrm{O}\right)$ 分布在 $\gamma-\mathrm{FeOOH}$ 表面, 或均匀 分布在 $\mathrm{Fe}_{3} \mathrm{O}_{4} / \gamma-\mathrm{Fe}_{2} \mathrm{O}_{3}$ 表面 ${ }^{[41]}$.

$\mathrm{PO}_{4}{ }^{3-}$ 主要通过配位作用、沉淀作用影响 nZVI 吸 附/还原铀的性能. 如酸性溶液中, nZVI 主要通过表面 配位作用 $\left(\equiv \mathrm{FePO}_{4} \mathrm{UO}_{2}\right)^{[125]}$ 和还原作用去除铀的主要机 理(式 16,17); 碱性条件下, $\mathrm{PO}_{4}{ }^{3-}$ 与铀离子形成沉淀(如 $\mathrm{UO}_{2} \mathrm{HPO}_{4} \bullet 4 \mathrm{H}_{2} \mathrm{O}$ )增强铀去除的效率 ${ }^{[18]}$ (式 22), 但是影响 $n Z V I$ 将 $U(V I)$ 还原至 $\mathrm{UO}_{2}$ 的程度 ${ }^{[18,112]}$. Qiu 等 ${ }^{[112]}$ 的研究 结果表明, $10 \mathrm{mg} / \mathrm{L}$ 的 $\mathrm{PO}_{4}{ }^{3-}$ 增强 $\mathrm{nZVI}$ 去除酸性至碱性

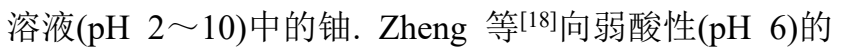
$\mathrm{U}(\mathrm{VI})(45 \mathrm{mg} / \mathrm{L})$ 中加入 $6 \mathrm{mg} / \mathrm{L} \mathrm{PO}_{4}{ }^{3-}$ 在 nZVI 颗粒表面形 成 “内层” 配合物, nZVI 表面等电点 $\left(\mathrm{pH}_{\mathrm{PZC}}\right)$ 由 5.5 降低 至 3.5. 由于 $\mathrm{PO}_{4}{ }^{3-}$ 在 $\mathrm{nZVI}$ 表面形成 $\mathrm{Fe}-\mathrm{U}-\mathrm{P}$ 配合物及 U-P 沉淀, 导致 nZVI 去除铀的准一级、准二级速率常数 分别由 $0.02 \mathrm{~min}^{-1}$ 和 $0.0008 \mathrm{~g} /(\mathrm{mg} \cdot \mathrm{min})$ 增加至 $0.09 \mathrm{~min}^{-1}$ 和 $0.0037 \mathrm{~g} /(\mathrm{mg} \bullet \mathrm{min})$, 铀的去除负荷 $(298 \mathrm{~K})$ 由 65.06 $\mathrm{mg} / \mathrm{g}$ 增加至 $79.13 \mathrm{mg} / \mathrm{g}$. Qiu ${ }^{[112]}$ 和 Zheng ${ }^{[18]}$ 才 队的研究
成果均表明低浓度的 $\mathrm{PO}_{4}{ }^{3-}$ 增强 nZVI 还原 U(VI) 的性能， Qiu 等 ${ }^{[112]}$ 进一步证明高浓度的 $\mathrm{PO}_{4}{ }^{3-}(50 \mathrm{mg} / \mathrm{L})$ 与铀形成 $\mathrm{UO}_{2} \mathrm{HPO}_{4} \bullet 4 \mathrm{H}_{2} \mathrm{O}$ 沉淀而降低 nZVI 还原 U(VI)的程度. 虽 然沉淀作用抑制了 nZVI 对 U(VI)的还原过程，但是，反 应后 $\mathrm{nZVI}$ 颗粒中 $\mathrm{UO}_{2}$ 的稳定性增强, 即 $\mathrm{UO}_{2}$ 被氧化的 程度和速率降低 ${ }^{[148]}$.

$\mathrm{CO}_{3}{ }^{2-}$ 和 $\mathrm{PO}_{4}{ }^{3-}$ 影响 $\mathrm{nZVI}$ 分离铀的原因主要包括: （1）与铀竞争吸附颗粒表面活性位点(式 14，15)降低铀 分离性能; (2) 改变颗粒表面电荷性质 ${ }^{[18]}$ (式 14, 15); (3) 在颗粒表面形成新的活性位点, 改变对铀的吸附性能 (式 14，15); (4) 与铀形成配合物, 改变铀被吸附和还原 的性能(式 16 20); (5) 与铀或铁形成沉淀(式 21, 22).

$$
\begin{gathered}
\equiv \mathrm{OH}+\mathrm{CO}_{3}{ }^{2-}+\mathrm{H}^{+} \leftrightarrow \equiv \mathrm{O}-\mathrm{CO}_{3} \mathrm{H}+\mathrm{H}_{2} \mathrm{O} \\
\equiv \mathrm{OH}+\mathrm{CO}_{3}{ }^{2-}+2 \mathrm{H}^{+} \leftrightarrow \equiv \mathrm{O}-\mathrm{CO}_{3}{ }^{-}+\mathrm{H}_{2} \mathrm{O} \\
\equiv \mathrm{OH}+\mathrm{UO}_{2}{ }^{2+}+\mathrm{CO}_{3}{ }^{2-} \leftrightarrow \equiv \mathrm{O}-\mathrm{UO}_{2} \mathrm{CO}_{3}{ }^{-}+\mathrm{H}^{+} \\
\equiv \mathrm{OH}+\mathrm{UO}_{2}{ }^{++}+2 \mathrm{CO}_{3}{ }^{2-} \leftrightarrow \equiv \mathrm{O}-\mathrm{UO}_{2}\left(\mathrm{CO}_{3}\right)_{2}{ }^{3-}+\mathrm{H}^{+} \\
2(\equiv \mathrm{OH})+\mathrm{UO}_{2}{ }^{2+}+\mathrm{CO}_{3}{ }^{2-} \leftrightarrow(2 \equiv \mathrm{O})-\mathrm{UO}_{2} \mathrm{CO}_{3}{ }^{2-}+2 \mathrm{H}^{+} \\
\mathrm{Fe}^{0}+\mathrm{UO}_{2}\left(\mathrm{CO}_{3}\right)_{3}{ }^{4-}+6 \mathrm{H}^{+} \leftrightarrow \mathrm{UO}_{2}+\mathrm{Fe}^{2+}+3 \mathrm{CO}_{2}+3 \mathrm{H}_{2} \mathrm{O} \\
\equiv \mathrm{OH}+\mathrm{UO}_{2}{ }^{2+}+\mathrm{PO}_{4}{ }^{3-} \leftrightarrow \equiv \mathrm{OUO}_{2} \mathrm{PO}_{4}{ }^{-} \\
\mathrm{UO}_{2}{ }^{2+}+2 \mathrm{Fe}^{2+}+2 \mathrm{PO}_{4}{ }^{3-} \leftrightarrow 2 \mathrm{FePO}_{4}(\mathrm{~s})+\mathrm{UO}_{2}(\mathrm{~s}) \\
\mathrm{UO}_{2}{ }^{2+}+\mathrm{PO}_{4}{ }^{3-}+\mathrm{H}^{+}+4 \mathrm{H}_{2} \mathrm{O} \leftrightarrow \mathrm{UO}_{2} \mathrm{HPO}_{4} \cdot 4 \mathrm{H}_{2} \mathrm{O}(\mathrm{s})
\end{gathered}
$$

(a)

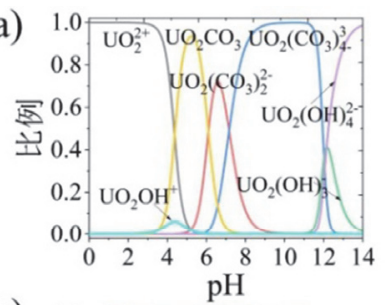

(b)

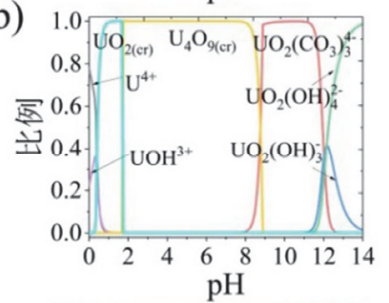

(c)

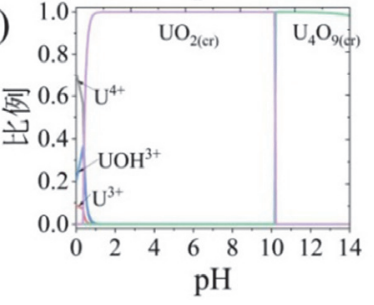

(d)

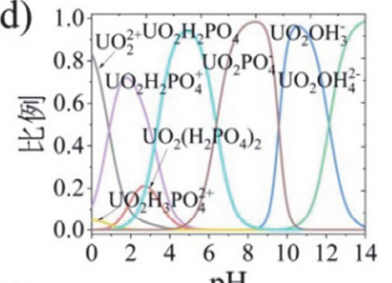

(e)
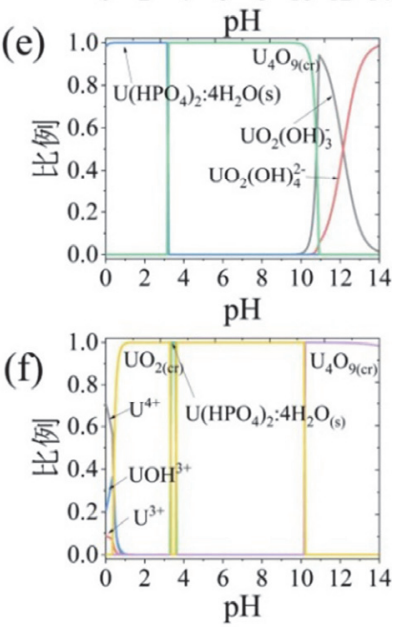

图 $825{ }^{\circ} \mathrm{C}$ 时, U-C-O-H $(\mathrm{a} \sim \mathrm{c})$ 和 U-P-O-H $(\mathrm{d} \sim \mathrm{f})$ 体系中不同 $\mathrm{pH}$ 条件 下各主要形态 $U$ 化合物的比例 $([\mathrm{U}]$ 总 $=0.001 \mathrm{mmol} / \mathrm{L},[\mathrm{C}]$ 总 $=10$ $\left.\mathrm{mmol} / \mathrm{L},[\mathrm{P}]_{\text {总 }}=10 \mathrm{mmol} / \mathrm{L}\right)$. (a, d) $E_{\mathrm{h}}=0.5 \mathrm{~V},(\mathrm{~b}, \mathrm{e}) E_{\mathrm{h}}=0 \mathrm{~V},(\mathrm{c}, \mathrm{f}) E_{\mathrm{h}}=$ $-0.5 \mathrm{~V}$

Figure 8 Fraction of uranium under different $\mathrm{pH}$ in the $\mathrm{U}-\mathrm{C}-\mathrm{O}-\mathrm{H}(\mathrm{a} \sim \mathrm{c})$ and U-P-O-H $(\mathrm{d} \sim \mathrm{f})$ systems at $25{ }^{\circ} \mathrm{C}\left([\mathrm{U}]_{\text {total }}=0.001 \mathrm{mmol} / \mathrm{L},[\mathrm{C}]_{\text {total }}=\right.$ $10 \mathrm{mmol} / \mathrm{L},[\mathrm{P}]_{\text {total }}=10 \mathrm{mmol} / \mathrm{L}$ ). (a, d) $E_{\mathrm{h}}=0.5 \mathrm{~V},(\mathrm{~b}, \mathrm{e}) E_{\mathrm{h}}=0 \mathrm{~V},(\mathrm{c}, \mathrm{f})$ $E_{\mathrm{h}}=-0.5 \mathrm{~V}$ 


\subsection{3 阳离子}

含铀废水中的阳离子包括 $\mathrm{Fe} 、 \mathrm{Ca} 、 \mathrm{Mg} 、 \mathrm{Na}$ 等. 阳 离子单独存在时, 其对 nZVI 去除铀的影响包括: (1) 改 变电子供体还原铀的效率, 如 $\mathrm{Fe}(\mathrm{II})$; (2) 与 U(VI)形成 配合物或占据 nZVI 颗粒表面吸附位点, 降低 nZVI吸附 铀的性能, 如 $\mathrm{Ca} 、 \mathrm{Mg}$ 和 $\mathrm{Na}$ 等.

$\mathrm{nZVI}$ 与含铀废水的反应体系中的 $\mathrm{Fe}$ 包括离子态的 $\mathrm{Fe}(\mathrm{II})$, 以及 $\mathrm{nZVI}$ 壳层的铁氧化物(如 $\mathrm{Fe}_{3} \mathrm{O}_{4}, \mathrm{Fe}_{2} \mathrm{O}_{3}$, $\mathrm{FeOOH}$ 和绿锈)晶体中或表面结合态 $\mathrm{Fe}(\mathrm{II}) . \mathrm{Fe}(\mathrm{II})$ 主要 影响均相反应和非均相反应体系中 U(VI) 的还原过程. 但是研究人员对两种反应体系中 $\mathrm{Fe}(\mathrm{II})$ 对 $U(V I)$ 的还原 能力尚未形成一致的观点. 如均相反应体系中, 热动力 学计算表明溶解态 $\mathrm{Fe}(\mathrm{II})$ 可还原 U(VI)离子, 但是, 不同 学者的实验结论与理论结算结果并不完全一致. Yan ${ }^{[96]}$ 和 Liger ${ }^{[144]}$ 等证明在 $\mathrm{pH}$ 为 6.9 7.5 条件下, U(VI) $(5 \times$ $\left.10^{-4} \sim 0.2 \mathrm{mmol} / \mathrm{L}\right)$ 未被离子态的 $\mathrm{Fe}(\mathrm{II})(0.16 \sim 1$ $\mathrm{mmol} / \mathrm{L})$ 还原; 而 $\mathrm{Du}$ 等 ${ }^{[149]}$ 证明溶液初始 $\mathrm{pH}$ 从 6.52 增 加至 $10.77, \mathrm{Fe}(\mathrm{II})$ 离子还原 $\mathrm{U}(\mathrm{VI})$ 的效率从 $53 \%$ 增加至 $97 \%$. Taylor 等 ${ }^{[150]}$ 进一步证明均相体系 $(\mathrm{pH}$ 7.2) 中, U(VI) $(0.02 \sim 0.16 \mathrm{mmol} / \mathrm{L})$ 首先形成沉淀 $\left(\beta-\mathrm{UO}_{2}(\mathrm{OH})_{2}\right.$ 和 $\left.\mathrm{UO}_{3} \cdot 2 \mathrm{H}_{2} \mathrm{O}\right)$, 然后被 $\mathrm{Fe}(\mathrm{II})(1 \mathrm{mmol} / \mathrm{L})$ 还原至 $\mathrm{U}(\mathrm{V})$ 或
U(IV). 非均相反应体系中, 众多学者一致认为 nZVI 颗 粒表面的结合态 $\mathrm{Fe}(\mathrm{II})$ 可直接传递电子至 $\mathrm{U}(\mathrm{VI})$ 后将 $\mathrm{U}(\mathrm{VI})$ 还原至 U(IV) ${ }^{[47,85,94,96]}$. 同时结合态 Fe(II)对 U(VI) 的还原性能受到溶液化学条件(如 $\mathrm{pH}$ 、离子态 $\mathrm{Fe}(\mathrm{II})$ 浓 度、碳酸根 $)^{[47,85,94,96]}, \mathrm{nZVI}$ 壳层铁氧化物种类(如 $\mathrm{Fe}_{3} \mathrm{O}_{4}$, $\left.\mathrm{Fe}_{2} \mathrm{O}_{3}\right)^{[110,116]}$ 以及铀的配位形态的影响 ${ }^{[150]}$.

MEDUSA 理论计算结果表明, 与 U-O-H 体系中 $\mathrm{U}(\mathrm{VI}$ )的形态分布相比(图 9), $\mathrm{Ca} 、 \mathrm{Na}$ 和 $\mathrm{Mg}$ 可改变 U(VI) 与氢氧根间的配位反应、被电子供体还原的途径并形成 多种沉淀(如 $\mathrm{CaUO}_{4}$ 和 $\mathrm{Na}_{2} \mathrm{U}_{2} \mathrm{O}_{7}$ ) (图 10). $\mathrm{Ca} 、 \mathrm{Na}$ 和 $\mathrm{Mg}$ 同时可占据 nZVI 颗粒表面的反应位点并改变其表面净 电荷性质.

MEDUSA 计算及实验研究表明, $\mathrm{Na}$ 和 $\mathrm{Mg}$ 对 nZVI 去除铀的效率影响较弱, 而 $\mathrm{Ca}$ 的影响更加明 显 ${ }^{[48,71-72,77,82,151]}$. 如 $\mathrm{Mg}$ 浓度从 $20 \mathrm{mg} / \mathrm{L}$ 增加至 $100 \mathrm{mg} / \mathrm{L}$ 时, nZVI@SA/CMC-Ca 去除 U(VI)的负荷仅从 $9.06 \mathrm{mg} / \mathrm{g}$ 降低至 $8.67 \mathrm{mg} / \mathrm{g}^{[151]} . \mathrm{Ca}$ 浓度从 $0 \mathrm{mg} / \mathrm{L}$ 增加至 $40 \mathrm{mg} / \mathrm{L}$ 时, nZVI 去除 U(VI)的负荷降低 $17.99 \%, \mathrm{U}(\mathrm{VI})$ 被还原为 $\mathrm{U}(\mathrm{IV})$ 的速率降低 $6.5 \sim 11.8$ 倍 ${ }^{[48,71]}$; 并且 $\mathrm{Ca}$ 与 $\mathrm{U}(\mathrm{VI})$ 形 成的沉淀(如 $\mathrm{Ca}_{2} \mathrm{UO}_{2}\left(\mathrm{CO}_{3}\right)_{3} \cdot 10 \mathrm{H}_{2} \mathrm{O}$ 和 $\left.\mathrm{Ca}\left(\mathrm{UO}_{2}\right)_{2}\left(\mathrm{PO}_{4}\right)_{2}\right)$ 可进一步降低 nZVI 去除铀的效率 ${ }^{[152-153]}$.
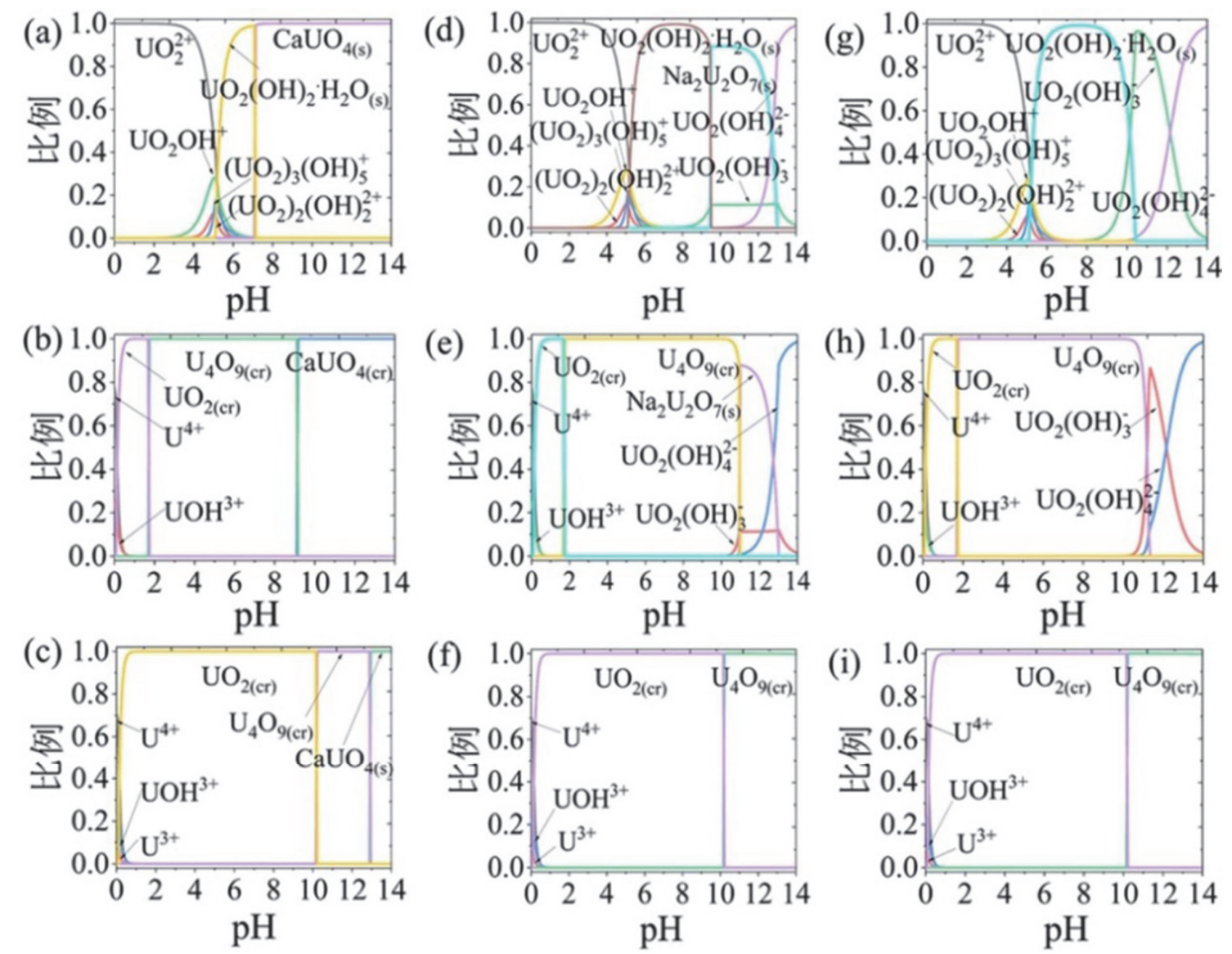

图 $925{ }^{\circ} \mathrm{C}$ 时, U-Ca-O-H $(\mathrm{a} \sim \mathrm{c}) 、 \mathrm{U}-\mathrm{Na}-\mathrm{O}-\mathrm{H}(\mathrm{d} \sim \mathrm{f})$ 和 $\mathrm{U}-\mathrm{Mg}-\mathrm{O}-\mathrm{H}(\mathrm{g} \sim \mathrm{i})$ 体系中不同 $\mathrm{pH}$ 条件下各主要形态 $\mathrm{U}$ 化合物的比例 $([\mathrm{U}]$ 总 $=0.01 \mathrm{mmol} / \mathrm{L}$, $\left.[\mathrm{Ca}]_{\text {总 }}=1 \mathrm{mmol} / \mathrm{L},[\mathrm{Na}]_{\text {总 }}=1 \mathrm{mmol} / \mathrm{L},[\mathrm{Mg}]_{\text {总 }}=1 \mathrm{mmol} / \mathrm{L}\right)$. $(\mathrm{a}, \mathrm{d}, \mathrm{g}) E_{\mathrm{h}}=0.5 \mathrm{~V},(\mathrm{~b}, \mathrm{e}, \mathrm{h}) E_{\mathrm{h}}=0 \mathrm{~V},(\mathrm{c}, \mathrm{f}, \mathrm{i}) E_{\mathrm{h}}=-0.5 \mathrm{~V}$

Figure 9 Fraction of uranium under different $\mathrm{pH}$ in the U-Ca-O-H $(\mathrm{a} \sim \mathrm{c}), \mathrm{U}-\mathrm{Na}-\mathrm{O}-\mathrm{H}(\mathrm{d} \sim \mathrm{f})$ and $\mathrm{U}-\mathrm{Mg}-\mathrm{O}-\mathrm{H}(\mathrm{g} \sim \mathrm{i})$ systems at $25{ }^{\circ} \mathrm{C}$. ([U $]_{\text {total }}=0.01$ $\left.\mathrm{mmol} / \mathrm{L},[\mathrm{Ca}]_{\text {total }}=1 \mathrm{mmol} / \mathrm{L},[\mathrm{Na}]_{\text {total }}=1 \mathrm{mmol} / \mathrm{L},[\mathrm{Mg}]_{\text {total }}=1 \mathrm{mmol} / \mathrm{L}\right) .(\mathrm{a}, \mathrm{d}, \mathrm{g}) E_{\mathrm{h}}=0.5 \mathrm{~V},(\mathrm{~b}, \mathrm{e}, \mathrm{h}) E_{\mathrm{h}}=0 \mathrm{~V},(\mathrm{c}, \mathrm{f}, \mathrm{i}) E_{\mathrm{h}}=-0.5 \mathrm{~V}$ 


\subsubsection{U/nZVI 物质的量比}

$n Z V I$ 通过表面吸附位点固定溶液中的 $U(V I)$, 且提 供电子供体(如 $\mathrm{Fe}(0)$ 和 $\mathrm{Fe}(\mathrm{II})$ ) 还原 $\mathrm{U}(\mathrm{VI})$. 因此, U/nZVI 的物质的量比对 nZVI 分离铀的性能及反应后产物的性 质有重要的影响. 根据 Langmuir 等温吸附模型, nZVI 吸附或还原铀的表面位点密度分别为 0.053 和 62.14 点/ $\mathrm{nm}^{2[78]}$. 如表 2 所示, 当 $\mathrm{U} / \mathrm{nZVI}$ 为 $5.5 \times 10^{-7} \sim 1.23$ 时, $\mathrm{nZVI}$ 可有效分离溶液中的铀 $\left(9.75 \times 10^{-6} \sim 3.57\right.$ $\mathrm{mmol} / \mathrm{L})$, 固液分离系数 $\left(K_{\mathrm{d}}\right)$ 比其它材料高数个数量 级 ${ }^{[154]}$. 相同的 $\mathrm{pH}$ 条件下, U/nZVI 升高后, nZVI 吸附或 还原 $\mathrm{U}(\mathrm{VI})$ 的效率逐渐降低. 如 $\mathrm{U} / \mathrm{nZVI}$ 从 $1.25 \times 10^{-1}$ 升 高至 $2.50 \times 10^{-1}$ 时, $\mathrm{U}(\mathrm{VI})$ 被分离的准一级速率常数从 $0.14 \mathrm{~min}^{-1}$ 降低至 $0.058 \mathrm{~min}^{-1}$ [72]; U/nZVI 从 $6.99 \times 10^{-2}$ 升高至 $9.79 \times 10^{-1}, \mathrm{U}(\mathrm{VI})$ 被还原的比例从 $99.3 \%$ 降低至 $66 \%{ }^{[50]}$.

\subsection{5 离子强度}

铀溶液的离子强度可影响 nZVI 颗粒的表面电势、 双电层的厚度, $\mathrm{U}(\mathrm{VI})$ 在铁氧化物层的配位形态 ${ }^{[155-156]}$ 以 及颗粒的腐蚀程度 ${ }^{[157-158]}$, 进而影响 nZVI 去除溶液中 $\mathrm{U}(\mathrm{VI})$ 的效率. $\mathrm{Liu}^{[43]}$ 和 $\mathrm{Xu}^{[82]}$ 等的研究结果表明, 由于 $0.01 \sim 1.0 \mathrm{~mol} / \mathrm{L}$ 的 $\mathrm{NaCl}(\mathrm{pH} 2 \sim 11$ )或 $0.001 \sim 0.1 \mathrm{~mol} / \mathrm{L}$ 的 $\mathrm{NaNO}_{3}$ ( $\mathrm{pH} 2 \sim 9$ ) 对铀的去除效率无影响, 而判定 $\mathrm{U}(\mathrm{VI})$ 在 nZVI 颗粒表面形成 “内层” 配合物. 衍射 X 射 线吸收精细结构(EXAFS) 图谱和表面配位模型分析结 果表明, $\mathrm{U}(\mathrm{VI})$ 与铁氧化物(如 $\mathrm{Fe}_{3} \mathrm{O}_{4} 、 \mathrm{Fe}_{2} \mathrm{O}_{3} 、 \alpha-\mathrm{FeOOH}$ ) 表面官能团均形成 “内层” 配合物, 且吸附效果不受离 子强度的影响 ${ }^{[109,159-161]}$. 但是, $\mathrm{Hu}$ 等 ${ }^{[80]}$ 的研究结果表明, $\mathrm{pH}<5.0$ 时，离子强度 $(\mathrm{NaCl}, 0.001 \sim 0.1 \mathrm{~mol} / \mathrm{L})$ 增加， $\mathrm{U}(\mathrm{VI})$ 的去除率降低; $\mathrm{pH} 5.0 \sim 11.0$ 时, 离子强度对 $\mathrm{U}(\mathrm{VI})$ 去除率无影响. 因此, U(VI)在 nZVI 颗粒表面形成
“外层” 配合物. 不同研究成果间的差异，可能是所用 nZVI 颗粒结构不同及实验条件差异所引起. U(VI)在 nZVI表面不同的配位形态影响其稳定性，因此，需通过 详实的实验及理论计算结果判明复杂水质条件中 U(VI) 在颗粒表面的配合物结构特征.

\section{2 .6 溶解氧}

$n Z V I$ 去除溶液中铀的主要机理是将 $U(V I)$ 还原为 $\mathrm{U}(\mathrm{IV})$, 而水溶液中的溶解氧严重影响 nZVI 去除/还原 $\mathrm{U}(\mathrm{VI})$ 的速率、负荷，以及反应后 nZVI 颗粒中铀的稳定 性 ${ }^{[75,162]}$. 首先, 溶解氧消耗 $\mathrm{nZVI}$ 中的 $\mathrm{Fe}(0)$ 和 $\mathrm{Fe}(\mathrm{II})$, 降

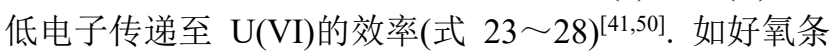
件下, nZVI 快速被溶解氧氧化成稳定的铁氧化物(如 $\mathrm{Fe}_{3} \mathrm{O}_{4}$ 和 $\left.\gamma-\mathrm{FeOOH}\right)\left(\right.$ 式 25 28 ${ }^{[163]}$. 其次, nZVI 中还原态 的铀(如 $\left.\mathrm{UO}_{2}(\mathrm{~s}) 、 \mathrm{U}_{3} \mathrm{O}_{8}\right)$ 会被溶解氧再次氧化为 $\mathrm{U}(\mathrm{VI})$ 后 释放至溶液 ${ }^{[73,75,92,147,164]}$. Riba ${ }^{[73]}$ 和 $\mathrm{Yan}^{[71]}{ }^{[\mathrm{N}}$ 分分别研究了 好氧和厌氧条件下, 足量 nZVI $(\mathrm{U} / \mathrm{nZVI}<3.0$, 物质的量 比)去除溶液中 $\mathrm{U}(\mathrm{VI})$ 的动力学过程. 研究结果表明, 厌 氧条件下, 溶液中的 $U(V I)$ 快速被去除, 且反应 $6 \mathrm{~h}$ 内 nZVI 颗粒表面的铀无明显的脱附现象; 好氧条件下, 反应 $30 \mathrm{~min}$ 后大量 nZVI 颗粒表面的 U(VI)脱附而进入 溶液. nZVI 被氧化的过程中, 溶液中呈现强氧化性、酸 性, 且 $\mathrm{Fe}$ (II) 离子浓度低, 不利于 nZVI 吸附、还原 铀 ${ }^{[41,50,77]}$. 当铀溶液初始 $\mathrm{pH}$ 为酸性的条件下, 溶解氧的 不利影响更为明显 ${ }^{[164]}$. 因此, 以 nZVI 处理酸性含铀废 水时宜维持体系为厌氧状态, 或适用硫化改性 nZVI 的 方式提高颗粒中已固定铀的稳定性.

$$
\begin{aligned}
& 2 \mathrm{Fe}^{0}+2 \mathrm{H}_{2} \mathrm{O}+\mathrm{O}_{2} \leftrightarrow 2 \mathrm{Fe}^{2+}+4 \mathrm{OH}^{-} \\
& \mathrm{Fe}^{2+}+5 / 2 \mathrm{H}_{2} \mathrm{O}+1 / 4 \mathrm{O}_{2} \leftrightarrow \mathrm{Fe}(\mathrm{OH})_{3}+2 \mathrm{H}^{+} \\
& 6 \mathrm{Fe}^{2+}+\mathrm{O}_{2}+6 \mathrm{H}_{2} \mathrm{O} \leftrightarrow 2 \mathrm{Fe}_{3} \mathrm{O}_{4}+12 \mathrm{H}^{+}
\end{aligned}
$$

\begin{tabular}{|c|c|c|c|c|c|c|c|c|}
\hline No. & $\mathrm{U} /\left(\mathrm{mmol} \cdot \mathrm{L}^{-1}\right)$ & $\mathrm{nZVI} /\left(\mathrm{mmol} \cdot \mathrm{L}^{-1}\right)$ & $\mathrm{U} / \mathrm{nZVI}$ & $\mathrm{pH}$ & 去除 & 还原 & $K_{\mathrm{d}} /\left(\mathrm{mL} \cdot \mathrm{g}^{-1}\right)$ & 文献 \\
\hline 1 & 0.04 & 17.86 & $2.24 \times 10^{-3}$ & 4.0 & $87 \%$ & - & $6.7 \times 10^{3}$ & {$[112]$} \\
\hline 2 & 0.08 & 17.86 & $4.48 \times 10^{-3}$ & 4.0 & $93 \%$ & 一 & $1.3 \times 10^{4}$ & [151] \\
\hline 3 & 0.25 & 35.71 & $7.00 \times 10^{-3}$ & 6.5 & $91 \%$ & $92 \%$ & $5.1 \times 10^{3}$ & [42] \\
\hline \multirow[t]{2}{*}{4} & 0.21 & 0.84 & $2.50 \times 10^{-1}$ & 7.0 & $100 \%$ & - & $2.1 \times 10^{6}$ & [72] \\
\hline & & 4.41 & $4.76 \times 10^{-2}$ & & & & $4.0 \times 10^{5}$ & \\
\hline 5 & 0.04 & 8.93 & $4.48 \times 10^{-3}$ & $6 \sim 11$ & $>95 \%$ & $\approx 58 \%$ & $3.8 \times 10^{4}$ & [80] \\
\hline 6 & 0.22 & 8.93 & $2.46 \times 10^{-2}$ & 6.0 & $99 \%$ & $82.7 \%$ & $1.0 \times 10^{6}$ & [41] \\
\hline \multirow[t]{2}{*}{7} & $9.75 \times 10^{-6}$ & 17.86 & $5.46 \times 10^{-7}$ & $3 \sim 11$ & $99 \%$ & - & $1.0 \times 10^{6}$ & [49] \\
\hline & $3.71 \times 10^{-3}$ & 17.86 & $2.08 \times 10^{-4}$ & & & & $2.5 \times 10^{4}$ & \\
\hline \multirow[t]{2}{*}{8} & 0.10 & 1.43 & $6.99 \times 10^{-2}$ & 5.0 & $98 \%$ & $99.3 \%$ & $1.2 \times 10^{6}$ & {$[50]$} \\
\hline & 1.40 & 1.43 & $9.79 \times 10^{-1}$ & & & $66 \%$ & $1.2 \times 10^{6}$ & \\
\hline 9 & 0.15 & 35.71 & $4.20 \times 10^{-3}$ & 7.0 & $98 \%$ & $97 \%$ & $2.5 \times 10^{4}$ & [78] \\
\hline 10 & 0.20 & 0.49 & $4.08 \times 10^{-1}$ & 6.9 & $99 \%$ & $99.8 \%$ & $3.6 \times 10^{6}$ & [71] \\
\hline 11 & $4.2 \times 10^{-4}$ & 1.79 & $2.35 \times 10^{-4}$ & 3.0 & $97 \%$ & $99 \%$ & $3.2 \times 10^{5}$ & [82] \\
\hline 12 & 0.50 & 44.64 & $1.12 \times 10^{-2}$ & 10.0 & $92 \%$ & - & $4.6 \times 10^{3}$ & [95] \\
\hline \multirow[t]{4}{*}{13} & 0.21 & 1.79 & $1.17 \times 10^{-1}$ & - & $99 \%$ & - & $9.9 \times 10^{5}$ & [94] \\
\hline & 0.42 & & $2.35 \times 10^{-1}$ & & $49 \%$ & & $9.6 \times 10^{3}$ & \\
\hline & 0.63 & & $3.52 \times 10^{-1}$ & & $29 \%$ & & $4.1 \times 10^{3}$ & \\
\hline & 0.84 & & $4.69 \times 10^{-1}$ & & $19 \%$ & & $2.4 \times 10^{3}$ & \\
\hline 14 & 3.57 & 2.90 & 1.23 & 6.5 & 98.88 & - & $6.1 \times 10^{5}$ & [73] \\
\hline
\end{tabular}

表 2 不同 $\mathrm{U} / \mathrm{nZVI}$ 物质的量比条件下 $\mathrm{nZVI}$ 分离铀的性能

Table 2 Efficiencies for the separation of uranium with nZVI under different U/nZVI molar ratio conditions 


$$
\begin{aligned}
& 4 \mathrm{Fe}^{0}+3 \mathrm{O}_{2}+2 \mathrm{H}_{2} \mathrm{O} \leftrightarrow 4 \gamma-\mathrm{FeOOH} \\
& 6 \mathrm{Fe}(\mathrm{OH})_{2}+\mathrm{O}_{2} \leftrightarrow 2 \mathrm{Fe}_{3} \mathrm{O}_{4}+6 \mathrm{H}_{2} \mathrm{O} \\
& 4 \mathrm{Fe}_{3} \mathrm{O}_{4}+\mathrm{O}_{2}+6 \mathrm{H}_{2} \mathrm{O} \leftrightarrow 12 \gamma-\mathrm{FeOOH}
\end{aligned}
$$

\subsection{7 温度}

随着铀溶液温度的变化, nZVI 与 $\mathrm{U}(\mathrm{VI})$ 的反应也呈 现规律性的变化趋势. 如溶液温度从 $5{ }^{\circ} \mathrm{C}$ 升高至 $55{ }^{\circ} \mathrm{C}$, $n Z V I$ 去除 U(VI) 的速率升高且 Langmuir 等温吸附模型 可高效拟合反应过程 ${ }^{[17,43,78,82,93,151]}$, 但是 $\mathrm{Hu}$ 等 ${ }^{[80]}$ 的研究 结果表明 Freundlich 等温吸附模型更适于模拟 U(VI)被 $n Z V I$ 吸附的过程. nZVI 与 $\mathrm{U}(\mathrm{VI})$ 反应的表观活化能为 $(28.5 \pm 0.435) \mathrm{kJ} / \mathrm{mol}, \Delta H 、 \Delta G$ 和 $\Delta S$ 分别为 $6.97 \sim 8.25$ $\mathrm{kJ} / \mathrm{mol} 、-5.40 \sim-23.26 \mathrm{~kJ} / \mathrm{mol}$ 和 $43.59 \sim 107.59$ $\mathrm{J} /(\mathrm{mol} \cdot \mathrm{K})$, 该过程属于物理吸附、吸热反应且反应短时 间内完成 ${ }^{[43,80,151]}$. 温度影响 nZVI 去除溶液中铀的原因 包括以下几点：(1)水溶液的温度影响铀的形态 ${ }^{[165-166]}$; (2)提高溶液中铀的活度; (3)改变 nZVI 壳层铁氧化物表

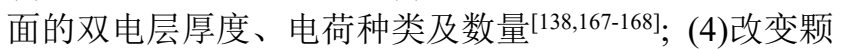
粒表面孔隙结构且促进铀在颗粒中的扩散 ${ }^{[43]}$.

\section{2 .8 反应时间}

nZVI 颗粒虽然可在数分钟内固定水溶液中的 $\mathrm{U}(\mathrm{VI})$, 但是颗粒中铀、铁化合物结构与稳定性随着反应 时间的延长而改变. 如 Crane 等 ${ }^{[77]}$ 应用 nZVI 修复含铀 自配水或铀矿山废水的研究结果表明 $0.5 \sim 2 \mathrm{~h}$ 内 $\mathrm{nZVI}$ 对铀的去除效率约为 99\%; 延长反应时间至 $24 \sim 672 \mathrm{~h}$ 导致 nZVI 颗粒中的铀再次释放至溶液中. 而利用炭黑 或镍等制备 nZVI 复合材料(如 CS-nZVI、nZVI/C、

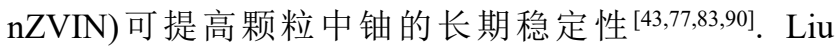
等 ${ }^{[43]}$ 的通过分析 $\mathrm{nZVI} / \mathrm{C}$ 与铀 $(\mathrm{pH} 3.0)$ 反应后颗粒的 EXAFS 图谱得出, 反应时间由 $1 \mathrm{~d}$ 延长至 $7 \mathrm{~d}$, 颗粒表面 吸附态的铀(U(VI)) 化合物逐渐被还原为 $\mathrm{UO}_{2}$, 铀的稳定 性增强. nZVI 颗粒中铀再次释放至溶液的过程中, 伴随 着 $\mathrm{Fe}$ 逐渐转变为 $5 \mathrm{Fe}_{2} \mathrm{O}_{3} \cdot 9 \mathrm{H}_{2} \mathrm{O} 、 \beta-\mathrm{FeOOH}$ 和 $\mathrm{Fe}_{3} \mathrm{O}_{4}$ 等铁 (氢)氧化物 ${ }^{[77,83,90]}$. 因此, 反应时间对 nZVI 分离水溶液 中铀的影响可归于以下三个方面: (1) nZVI 颗粒中吸附 态和还原态铀的稳定性, 即吸附态铀是否易于脱附或还 原态铀是否易于被氧化而从颗粒中再次释放至溶 液 ${ }^{[77,83,90]}$; (2) nZVI 颗粒中铀的价态, 即 U(VI) 被还原的 程度 ${ }^{[72]} ;(3)$ nZVI 的腐蚀速率及铁氧化物结构转化的途 径和程度 ${ }^{[73]}$.

\section{$4 \mathrm{nZVI}$ 处理含铀废水的应用}

铀矿石酸法和碱法浸出工艺所产生的废水包括被 铀污染的地下水或储存于地表的放射性水体(如浸渍水 等). nZVI 处理含铀废水的工艺分为原位处理(图 10a, 10b)和异位处理(图 10c)两类. 原位处理的方式包括以 外部动力驱动 $n Z V I$ 在地下水中循环或制备 nZVI 渗透 墙等. 在地下水流动的过程中, $n Z V I$ 将 $\mathrm{U}(\mathrm{VI})$ 从液相固
定至固相而实现水体净化 ${ }^{[35,86,89]}$. 异位修复包括将铀废 水转移至含有 $\mathrm{nZVI}$ 的污水处理装置中, 经多个反应阶 段而将 $\mathrm{U}(\mathrm{VI})$ 转移至固体颗粒中.

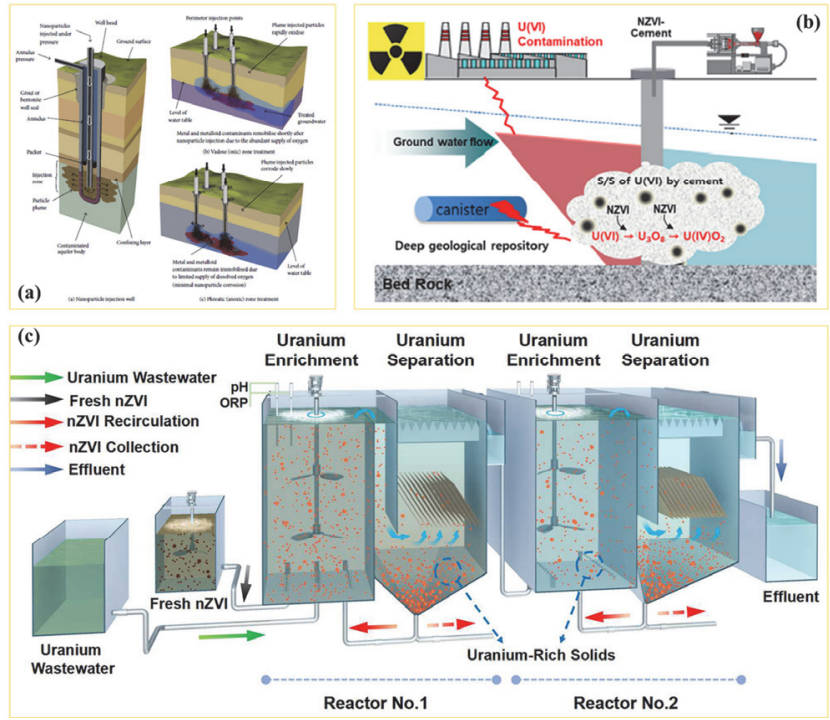

图 $10 \mathrm{nZVI}$ 处理含铀地下水 $\left(\mathrm{a}^{[89]} 、 \mathrm{~b}^{[35]}\right)$ 及铀尾矿库浸渍水 $\left(\mathrm{c}^{[51]}\right)$ 的工 艺示意图

Figure 10 Schematic diagram for the treatment of uranium-containing groundwater $\left(\mathrm{a}^{[89]}, \mathrm{b}^{[35]}\right)$ and uranium tailings wastewater $\left(\mathrm{c}^{[51]}\right)$

Hua 等 ${ }^{[51]}$ 结合 nZVI 与传统连续流工艺, 经过反应、 分离、循环等阶段实现 nZVI 对铀尾矿库浸渍水中 $\mathrm{U}(\mathrm{VI})$ 及其他(类)金属污染物的高效去除(图 10c). 该工艺稳定 运行过程中 (193 h), 少量 nZVI 颗粒(0.12 g-nZVI/L-废 水)处理 $497.7 \mathrm{~L}$ 铀尾矿库浸渍水, 富集回收 $149.94 \mathrm{mg}$, 出水中 $\mathrm{U}(\mathrm{VI})$ 的平均浓度 $(1.47 \mu \mathrm{g} / \mathrm{L})$ 远低于多国/地区饮 用水水质标准 $\left(\mathrm{USEPA}^{[169]}\right.$ 和 $\mathrm{WHO}^{[170]} 30 \mu \mathrm{g} / \mathrm{L}$, 加拿大 $20 \mu \mathrm{g} / \mathrm{L}{ }^{[171]}$, 德国 ${ }^{[172]} 10 \mu \mathrm{g} / \mathrm{L}$ 和 $2 \mu \mathrm{g} / \mathrm{L}$ ). 反应后 $\mathrm{nZVI}$ 颗粒中超过 $80 \%$ 的铀离子为 IV, 铀的平均质量含量为 $0.19 \%$ 且主要富集在颗粒中心区域. nZVI 颗粒对 U(VI) 的分离常数 $\left(1.30 \times 10^{6}\right)$ 远高于对其它污染物质 $(1.28 \times$ $\left.10^{4} \sim 3.53 \times 10^{5}\right)$. 但是，该工艺优点是可通过调节工艺 参数实时控制出水水质和固相产物的安全性, 缺点是需 要酸性、氧化性的浸渍水导致 nZVI 被腐蚀消耗程度高, 且 nZVI 对 Mn 等金属离子的去除效率较差等问题.

\section{5 结论与展望}

铀是重要的能源物质, 其对我国核能发展及实现碳 中和目标(2060 年)具有战略意义. 但是, 铀矿开采过程 及核电安全事故易对生态安全及人体健康产生长期不 利影响.日本福岛核电站(2011 年)泄露的放射性物质 (如 $\mathrm{Cs} 、 \mathrm{U} 、 \mathrm{Pu} 、 \mathrm{Sr})^{[13-14]}$ 已对全球海洋、陆地、大气等 生态系统带来短期内不可逆转的破坏. 我国 “十四五” 规划明确要求发展核电能源的同时应注重放射性污染 物质的防治工作. 因此，基于放射性废水的水质特征和 铀的理化性质研发高效环境修复材料与工艺具有重要 
的社会及环境意义.

国内外众多团队的研究结果表明 nZVI 可高效分离 水溶液中低浓度的 U(VI). 但是, 建立稳定性高、可靠性 强且成本低的铀废水处理工程, 仍需开展大量实验研究 以解决重要的理论及应用难题:

(1) Fe、U 环境化学行为的理论研究

在 nZVI-U 体系中, nZVI 去除 $U$ 的反应是由一系列 溶液、固液界面和固相反应组成的动态平衡过程. nZVI 的结构特征易受水质组分和暴露时间的影响而发 生变化. 因此, 需综合利用材料分析表征和理论计算阐 明该复杂体系中 nZVI 的结构转化规律(如表面官能团、 表面电荷、物相组成、磁性粒径、形貌、密度)、确定 水质因素协同作用对 nZVI 固定 U 的动力学过程的影响; $\mathrm{Fe}-\mathrm{U}$ 间化学反应机理(如表面配位机制、电子传递效率 和途径、晶格嵌入-原子置换原理).

(2) nZVI 复合材料的结构设计与性能评价

nZVI 及其复合材料处理含铀废水应具备的基本性 能包括去除铀的速率快、负荷高、选择性高、稳定性强 等. nZVI 颗粒的结构设计需同时考虑含铀浸渍水、地下 水的水质特征及水处理工艺应用场景. 当水溶液中含有 常见阴离子、阳离子和有机物时, 多种 nZVI 复合材料 可实现高效分离固定铀的目的. 但是, nZVI 去除铀废水 中 Cs 等放射性核素的性能不理想. 因此耦合 nZVI 与共 存放射性核素专有修复材料的性能, 对放射性废水的净 化处理具有重要意义. 此外, 含铀废水的原位、异位处 理工艺对 nZVI 复合材料的性能要求存在差异. 如应用 “反应-循环-分离” 工艺异位处理铀尾矿浸渍水时, nZVI 良好的沉降分离性能(重力沉降、磁分离)对工艺的运行 参数(如水力停留时间、回流比)有重要影响. 而应用 $n Z V I$ 修复含铀地下水时, 则要求 nZVI 具备良好的迁移 性能而实现对较大区域内受污染地下水的修复. 最后, nZVI-U 颗粒中铀的长期稳定性(如吸附/解吸、再氧化) 和生态毒性是材料功能化设计必须关注的关键问题.

（3）放射性废水处理工艺的控制理论及模型

放射性废水治理工艺的自动化控制方法可为水质 达标排放、设备安全运行及人员健康提供重要保障. 分 析铀的吸附/解吸、还原/再氧化、沉淀/溶解等动态过程 与水质组分及工艺运行参数间的数学相关性, 可为建立 监测和调控 nZVI 固定铀的方法提供依据.

\section{作者简介}

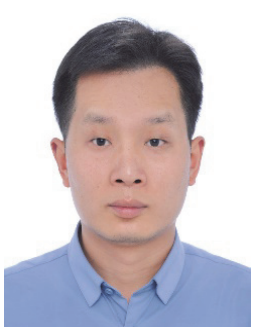

滑熠龙, 南华大学环境科学与工程系教师. 同济大学环 境科学与工程专业博士, 东华大学材料科学与工程专业博士
后. 主要从事铁基纳米材料的研发及应用, 放射性废水污染 控制及资源化的研究及实践工作. 已成功应用 nZVI 连续流工 艺治理铀尾矿库含铀废水.

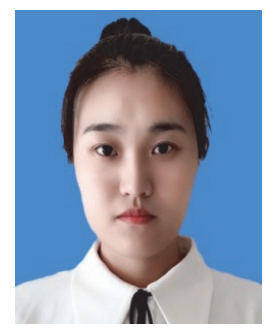

李冬涵, 南华大学资源环境与安全工程学院 2020 级硕士 生, 研究方向为资源与环境.

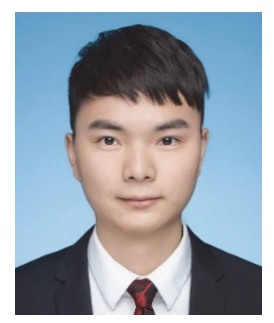

顾天航, 同济大学环境科学与工程学院 2018 级博士生, 研究方向为纳米零价铁富集水中稀有元素.

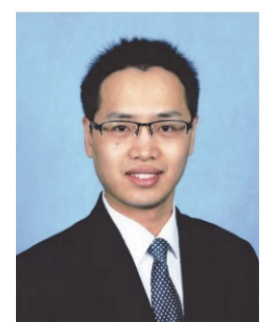

王伟, 博士, 同济大学化学专业博士后, 主要从事铁基纳 米材料用于重金属污染控制及资源化方面的研究及实践工作, 作为主要完成人之一将铁基纳米技术成功应用于复杂多金属 废水处理工程, 已发表 SCI 论文 10 余篇.

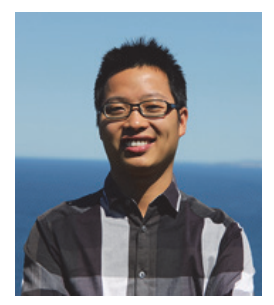

杨建平, 东华大学研究员、博士生导师. 2013 年获复旦大 学无机化学博士学位, 在同济大学、澳大利亚伍伦贡大学、澳 大利亚莫纳什大学进行博士后和访学研究. 2016 年加入东华 大学从事无机材料界面调控及环境资源应用研究, 发表 SCI 论文 130 多篇, 总引用 10000 余次, $\mathrm{H}$ 指数 46. 担任 Environmental Protection Research 副主编; 荣获上海市东方学 者特聘教授(2017 年)、上海千人 $(2018$ 年)、霍英东青年基金 (2020 年); 入选英国皇家化学会 JMCA 和 ChemComm 新锐科 学家(Emerging Investigators, 2020 和 2021 年). 


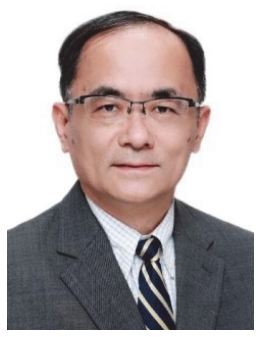

张伟贤, 教授, 博士生导师, “千人计划”国家特聘专家, 2011 年 5 月起任污染控制与资源化研究国家重点实验室主任. 1984 年毕业于同济大学, 1996 年获美国约翰·霍普金斯大学 (The Johns Hopkins University)环境工程博士学位, 曾任美国 里海大学(Lehigh University)教授. 2000 年获美国国家科学基 金会(NSF)青年教授奖(CAREER AWARD). 主持过国家自然 科学基金海外及港澳学者合作研究基金及多项国家自然科学 基金. 长期致力于环境中重金属及持久性有机污染物的基础 与应用研究, 是环境纳米技术的先驱之一, 纳米零价铁技术 的创始研究者. 在纳米零价铁合成、表征、污染物反应机理、 应用于地下水修复及废水处理方面发表了系列经典论文.

\section{References}

[1] Canu, I. G.; Jacob, S.; Cardis, E.; Wild, P.; Cae, S. r; Acker, A.; Tirmarche, M.; Laurier, D. Am. J. Epidemiol. 2011, 68, Suppl 1.

[2] Träber, S.C.; Höllriegl, V.; Li, W.-B.; Czeslik, U.; Rühm, W.; Oeh, U.; Michalke, B. Environ. Sci. Technol. 2014, 48, 24.

[3] Wu, Y.; Wang, Y.-X.; Xie, X.-J. Sci. Total Environ. 2014, 472, 809

[4] Winde, F.; Erasmus, E.; Geipel, G. Sci. Total Environ. 2017, 574, 400.

[5] Bister, S.; Birkhan, J.; Lüllau, T.; Bunka, M.; Solle, A.; Stieghorst, C.; Riebe, B.; Michel, R.; Walther, C. J. Environ. Radioactiv. 2015, $144,21$.

[6] Cinelli, G.; Tondeur, F.; Dehandschutter, B.; Bossew, P.; Tollefsen, T.; De Cort, M. J. Environ. Radioactiv. 2017, 166, 220.

[7] Haribala; Hu, B.; Wang, C.; Gerilemandahu; Xu, X.; Zhang, S.; Bao, S.; Li, Y. China, Ecotox. Environ. Safe. 2016, 130, 185.

[8] Shelley, R.; Kim, N.-S.; Parsons, P. J.; Lee, B.-K.; Agnew, J.; Jaar, B. G.; Steuerwald, A. J.; Matanoski, G.; Fadrowski, J.; Schwartz, B. S.; Todd, A. C.; Simon, D.; Weaver, V. M. J. Expo. Sci. Env. Epid. 2013, 24, 58.

[9] Kreuzer, M.; Fenske, N.; Schnelzer, M.; Walsh, L. Brit. J. Cancer $\mathbf{2 0 1 5}, 113,1367$.

[10] Ohba, T.; Tanigawa, K.; Liutsko, L. Environ. Int. 2021, 148, 106379.

[11] Murugan, R.; Kavasi, N.; Sahoo, S. K.; Omori, Y.; Sorimachi, A.; Takahashi, H.; Aono, T. J. Environ. Radioactiv. 2021, 232, 106568-106568.

[12] Hirouchi, J.; Takahara, S.; Yoshimura, K. J. Environ. Radioactiv. 2021, 232, 106572-106572.

[13] Zuykov, M.; Fowler, S. W.; Archambault, P.; Spiers, G.; Schindler, M. Mar. Pollut. Bull. 2020, 151, 110860.

[14] Miki, S.; Fujimoto, K.; Shigenobu, Y.; Ambe, D.; Kaeriyama, H.; Takagi, K.; Ono, T.; Watanabe, T.; Sugisaki, H.; Morita, T. Fish. Oceanogr. 2017, 26, 221.

[15] Wang, Y.-N. China Econ. Wkly. 2020, (20), 92-95 (in Chinese). (王 亦楠，中国经济周刊, 2020, (20), 92-95.)

[16] Jin, Y Glob. Times 2021, 15 (in Chinese). (金嬴，环球时报, 2021, 15.)

[17] Zhang, Q.; Wang, Y.; Wang, Z.; Zhang, Z.; Wang, X.; Yang, Z. J. Alloy. Compd. 2021, 852,156993.

[18] Zheng, H.; Ren, X.; Zhang, X.; Song, G.; Chen, D.; Chen, C. J. Mol. Liq. 2020, 297, C.

[19] Zhao, X.; Liu, W.; Cai, Z.; Fu, J.; Duan, J.; Zhao, D.; M. Bozack; Feng, Y. Colloid Surface A. 2020, 604,125315.

[20] Zhang, Y.; Cheng, W.; Huang, Z.; Nie, X.; Chi, F.; Pan, N.; Ding, C. J. Radioanal. Nucl. Ch. 2020, 326, 845 .

[21] Yang, F.; Xie, S.; Wang, G.; Yu, C.W.; Liu, H.; Liu, Y. Environ. Sci. Pollut. R. 2020, 27,20246.
[22] Xiao, M.; Hu, R.; Cui, X.; W. Gwenzi; C. Noubactep. Processes, $2020,8,409$.

[23] Xiao, M.; Cui, X.; Hu, R.; W. Gwenzi; C. Noubactep. Processes, 2020, 8,1162 .

[24] Xiao, J.; Pang, Z.; Zhou, S.; Chu, L.; Rong, L.; Liu, Y.; Li, J.; Tian, L. Sep. Purif. Technol. 2020, 244, 116667.

[25] Xiang, S.; Cheng, W.; Chi, F.; Nie, X.; T. Hayat; N.S. Alharbi. Acs Appl. Nano Mater. 2020, 3, 1131.

[26] Wang, S.; Wang, L.; Li, Z.; Zhang, P.; Du, K.; Yuan L.; Ning S.; Wei, Y.; Shi, W. J. Hazard. Mater. 2020, 408, 124949.

[27] Wang, J.; Pang, H.; Tang, H.; Yu, S.; Zhu, H.; Wang, X. J. Inorg. Mater. 2020, 35, 373.

[28] Sharma, N.; Ghosh, A.; Fortner, J. D.; Giammar, D. E. Environ. Sci.-Nano 2020, 7, 2010.

[29] Liao, H.; Yu, J.; Zhu, W.; Kuang, M.; Duan T.; Zhang, Y.; Lin, X.; Luo, X.; Zhou, J. Appl. Surf. Sci. 2020, 507, 145075.

[30] Duan, J.; Ji, H.; Zhao, X.; Tian, S.; Liu, X.; Liu, W.; Zhao, D. Chem. Eng. J. 2020, 393, 124692.

[31] Zhang, Q.; Zhao, D.; Feng, S.; Wang, Y.; Jin, J.; Alsaedi A.; Hayat T.; Chen, C. J. Colloid Interf. Sci. 2019, 552, 735.

[32] Zhang, H.-M.; Ruan, Y.; Liang, A.-P.; Shih, K. M.; Diao, Z. H.; Su, M. H.; Hou, L. A.; Chen, D. Y.; Lu, H.; Kong, L. J. J. Clean. Prod. 2019, 239, 117873.

[33] Yu, S.; Wang, X.; Liu, Y.; Chen, Z.; Wu, Y.; Liu, Y.; Pang, H.; Song, G.; Chen, J.; Wang, X. Chem. Eng. J. 2019, 365, 51.

[34] Wang, M.; Cheng, W.; Wan, T.; Hu, B.; Zhu, Y.; Song, X.; Sun, Y. Chem. Eng. J. 2019, 362, 99.

[35] Sihn, Y.; Bae, S.; Lee, W. Chemosphere 2019, 215, 626.

[36] Pang, H.; Diao, Z.; Wang, X.; Ma, Y.; Yu, S.; Zhu, H.; Chen, Z.; Hu, B.; Chen, J.; Wang, X. Chem. Eng. J. 2019, 366, 368.

[37] Lv, Z.; Yang, S.; Chen, L.; Alsaedi, A.; Hayat, T.; Chen, C. J. Environ. Sci. 2019, 76, 377.

[38] Li, X.; Li, Y.; Wu, Q.; Zhang, M.; Guo, X.; Li, X.; Ma, L.; Li, S. Chem. Eng. J. 2019, 365, 70.

[39] Duan, J.; Ji, H.; Liu, W.; Zhao, X.; Han, B.; Tian, S.; Zhao, D. Chem. Eng. J. 2019, 359, 1617.

[40] Kong, L.-J.; Zhang, H.-M.; Shih, K.M.; Su, M.-H.; Diao, Z.-H.; Long, J.-Y.; Hou, L.-A.; Song, G.; Chen, D.-Y. J. Hazard. Mater. 2018, 357, 168.

[41] Hua, Y.; Wang, W.; Huang, X.; Gu, T.; Ding, D.; Ling, L.; Zhang, W.-X. Chemosphere 2018, 201, 603.

[42] Ding, C.-C.; Cheng, W.-C.; Nie, X.-Q.; Yi, F.-C.; Xiang, S.-H.; Asiri A.M., Marwani. H.M. J. Ind. Eng. Chem. 2018, 61, 236.

[43] Liu, H.; Li, M.; Chen, T.; Chen, C.; N.S. Alharbi; Hayat T.; Chen, D.; Zhang, Q.; Sun, Y. Environ. Sci.Technol. 2017, 51, 9227.

[44] Hu, S.-H.; Lin, X.-Y.; Zhang, Y.-H.; Shi, M.-L.; Luo, X.-G. J. Radioanal. Nucl. Ch. 2017, 314, 2405.

[45] Shao, D.-D.; Wang, X.-X.; Wang, X.-L.; Hu, S.; Hayat T.; Alsaedi A.; Li, J.-X.; Wang, S.-H.; Hu, J.; Wang, X.-K. Rsc Adv. 2016, 6 , 52076.

[46] Kong, L.-J.; Zhu, Y.-T.; Wang, M.; Li, Z.-X.; Tan, Z.-C.; Xu, R.-B.; Tang, H.-M.; Chang, X.-Y.; Xiong, Y.; Chen, D.-Y. J. Hazard. Mater 2016, 320, 435.

[47] Hu, B.-W.; Ye, F.; Ren, X.-M.; Zhao, D.-L.; Sheng, G.-D.; Li, H.; Ma, J.-Y.; Wang, X.-K.; Huang, Y.-Y. Environ. Sci.-Nano, 2016, 3, 1460.

[48] Zhang, Z.; Liu, J.; Cao, X.; Luo, X.; Hua, R.; Liu, Y.; Yu, X.; He, L.; Liu, Y. J. Hazard. Mater. 2015, 300, 633.

[49] Ling, L.; Zhang, W.-X. J. Am. Chem. Soc. 2015, 137, 2788.

[50] Li, Z.-J.; Wang, L.; Yuan, L.-Y.; Xiao, C.-L.; Mei, L.; Zheng, L.-R.; Zhang, J.; Yang, J.-H.; Zhao, Y.-L.; Zhu, Z.-T.; Chai, Z.-F.; Shi, W.-Q. J. Hazard. Mater. 2015, 290, 26.

[51] Hua, Y.-L.; Wang, W.; Hu, N.; Gu, T.; Ling, L.; Zhang, W.-X. Environ. Sci-Nano 2021, 8,666

[52] Sun, Y.-P.; Li, X.-Q.; Cao, J.; Zhang, W.-X.; Wang, H.-P. Adv. Colloid Interfac. 2006, 120, 47.

[53] Kumar, M. A.; Bae, S.; Han, S.; Chang, Y.; Lee, W. J. Hazard. Mater. 2017, 340, 399.

[54] Bhattacharjee, S.; Ghoshal, S. Environ. Sci. Technol. 2016, 50, 8631.

[55] Nunez Garcia, A.; Boparai, H. K.; O'Carroll, D. M. Environ. Sci. Technol. 2016, 50, 5243.

[56] Bae, S.; Hanna, K. Environ. Sci. Technol. 2015, 49, 10536.

[57] Xu, C.-H.; Zhang, B.-L.; Wang, Y.-H.; Shao, Q.-Q.; Zhou, W.-Z.; Fan, D.-M.; Bandstra, J. Z.; Shi, Z.-Q.; Tratnyek, P. G. Environ. Sci. Technol. 2016, 50, 11879 . 
[58] He, Y.; Gao, J.-F.; Feng, F.-Q.; Liu, C.; Peng, Y.-Z.; Wang, S.-Y. Chem. Eng. J. 2012, 179, 8.

[59] Gu, Y.; Wang, B.; He, F.; Bradley, M. J.; Tratnyek, P. G. Environ. Sci. Technol. 2017, 51, 12653.

[60] Hua, Y.-L.; Xia, X.-F.; Huang, X.-Y.; Ling, L.; Zhang, W.-X. Acta Chim. Sinica 2017, 75, 594 (in Chinese). (滑熠龙, 夏雪芬, 黄潇 月，凌岗，张伟贤，化学学报, 2017, 75, 594.)

[61] Xie, Y.; Dong, H.; Zeng, G.; Zhang, L.; Cheng, Y.; Hou, K.; Jiang, Z.; Zhang, C.; Deng, J. J. Hazard. Mater. 2017, 338, 306.

[62] Su, Y.-M.; Adeleye A.S., Keller A.A., Huang, Y.-X.; Dai, C.-M.; Zhou, X.-F.; Zhang, Y.-L. Water Res. 2015, 74, 47.

[63] Dong, H.; Deng, J.; Xie, Y.; Zhang, C.; Jiang, Z.; Cheng, Y.; Hou, K.; Zeng, G. J. Hazard. Mater. 2017, 332, 79.

[64] Ling, L.; Huang X.-Y.; Li, M.; Zhang, W.-X. Environ. Sci.Technol. 2017, 51, 14293

[65] Gu, T.-H.; Shi, J.-M.; Hua, Y.-L.; Liu, J.; Wang, W.; Zhang, W.-X. Acta Chim. Sinica 2017, 75, 991 (in Chinese). (顾天航, 石君明, 滑 熠龙，刘静，王伟，张伟贤，化学学报, 2017, 75, 991.)

[66] Ling, L.; Huang, X.-Y.; Zhang, W.-X. Adv. Mater. 2018,30, 1705703.

[67] Huang, X.-Y.; Wang, W.; Ling, L.; Zhang, W.-X. Acta Chim. Sinica 2017, 75, 529 (in Chinese). (黄潚月, 王伟, 凌岗, 张伟贤, 化学学 报, 2017, 75, 529.)

[68] Wang, W.; Li, S.-L.; Lei, H.; Pan, B.-C.; Zhang, W.-X. Chem. Eng. J. 2015, 260, 616.

[69] Li, S.-L.; Wang, W.; Liu, Y.-Y.; Zhang, W.-X. Chem. Eng. J. 2014, $254,115$.

[70] Elliott, D. W.; Zhang, W.-X. Environ. Sci. Technol. 2001, 35, 4922.

[71] Yan, S.; Hua, B.; Bao, Z.-Y.; Yang, J.; Liu, C.-X.; Deng, B.-L. Environ. Sci. Technol. 2010, 44, 7783.

[72] Tsarev, S.; Collins, R. N.; Ilton, E. S.; Fahy, A.; Waite, T. D. Environ. Sci.-Nano 2017, 4, 1304.

[73] Riba, O.; Scott, T. B.; Ragnarsdottir, K. V.; Allen, G. C. Geochim. Cosmochim. Ac. 2008, 72, 4047.

[74] Burghardt, D.; Kassahun, A. Environ. Geol. 2005, 49, 314.

[75] Dickinson, M.; Scott, T. B. J. Hazard. Mater. 2010, 178, 171.

[76] Li, X.-Y.; Zhang, M.; Liu Y.-B.; Li X.; Yang, B.; Hua, R.; Liu, Y.-H. Chin. J. Nonferrous Met. 2015, 25, 3505 (in Chinese). (李小燕, 张 明, 刘义保, 李寻, 杨波, 花榕, 刘云海, 中国有色金属学报, 2015, 25, 3505.)

[77] Crane, R. A.; Pullin, H.; Scott, T. B. Chem. Eng. J. 2015, 277, 252.

[78] Ding, C.; Cheng, W.; Sun, Y.; Wang, X.; Geochim. Cosmochim. Ac. 2015, 165,86 .

[79] Chen, H.-J.; Huang, H.-S.; Zhang, Z.-B.; Liu, Y.-H; Wang, X.-K. Acta Chim. Sinica 2017, 75, 560 (in Chinese). (陈海军, 黄舒怡, 张 志宾, 刘云海, 王祥科, 化学学报, 2017, 75, 560.)

[80] Hu, B.; Mei, X.; Li, X.; Hu, J.; Xu, D.; Ma, J.; Huang, Y. J. Mol. Liq. 2017, 237, 1.

[81] Crane, R. A.; Scott, T. J. Nanopart. Res. 2014, 16, 2813.

[82] Xu, J.-L.; Li, Y.-L.; Jing, C.; Zhang, H.-C.; Ning, Y. J. Radioanal. Nucl. Ch. 2014, 299, 329.

[83] Crane, R.; Pullin, H.; Macfarlane, J.; Silion, M.; Popescu, I.; Andersen, M.; Calen, V.; Scott, T. J. Environ. Eng. 2015, 141, 04015011

[84] Jing, C.; Li, Y.; Cui, R.; Xu, J. J. Radioanal. Nucl. Ch. 2015, 304,859 .

[85] Sheng, G.-D.; Yang, P.-J.; Tang, Y.-N.; Hu, Q.-Y.; Li, H.; Ren, X.-M.; Hu, B.-W.; Wang, X.-K.; Huang, Y.-Y. Appl. Catal. B-Environ. 2016, $193,189$.

[86] Cantrell, K. J.; Kaplan, D. I.; Wietsma, T. W. J. Hazard. Mater. 1995, 42, 201.

[87] Tsarev, S.; Collins, R. N.; Fahy, A.; Waite, T. D. Environ. Sci. Technol. 2016, 50, 2595.

[88] Crane, R. A.; Dickinson, M.; Scott, T. B. Chem. Eng. J. 2015, 262, 319.

[89] Crane, R. A.; Scott, T. B. J. Nanomater. 2014, 956360, 1.

[90] Crane, R. A.; Scott, T. J. Nanopart. Res. 2014, 16, 2813.

[91] Popescu, I. C.; Filip, P.; Humelnicu, D.; Humelnicu, I.; Scott, T. B.; Crane, R. A. J. Nucl. Mater. 2013, 443, 250.

[92] Crane, R. A.; Scott, T. B. J. Nanotech. 2013, 173625, 1.

[93] Li, X.; Zhang, M.; Liu, Y.; Li, X.; Liu, Y.; Hua, R.; He, C. Water Qual. Expos. Hea. 2013, 5, 31.

[94] Sheng, G.-D.; Shao, X.-Y.; Li, Y.-M.; Li, J.-F.; Dong, H.-P.; Cheng, W.; Gao, X.; Huang, Y.-Y. J. Phys. Chem. A. 2014, 118, 2952.

[95] Sun, Y.; Ding, C.; Cheng, W.; Wang, X. J. Hazard. Mater. 2014, 280,399.

[96] Yan, S.; Chen, Y.-H.; Xiang, W.; Bao, Z.-Y.; Liu, C.-X.; Deng, B.-L. Chemosphere 2014, 117, 625 .
[97] Li, J.-H.; Yang, L.-X.; Li, J.Q.; Yin, W.-H.; Tao, Y.; Wu, H.-Q.; Luo, F. J. Solid State Chem. 2019, 269, 16.

[98] Xu, J.; Avellan A.; Li, H.; Liu, X.; Noel V.; Lou, Z.; Wang, Y.; Kaegi R.; Henkelman G.; Lowry. G.V. Adv. Mater. 2020,32, 1906910.

[99] Xu, J.; Avellan A.; Li, H.; Clark E.A.; Henkelman G.; Kaegi R.; Lowry. G.V. Environ. Sci.Technol. 2020,54,13294.

[100] Li, J.; Zhang, X.; Sun, Y.; Liang, L.; Pan, B.-C.; Zhang, W.; Guan, X. Environ. Sci.Technol. 2017,91,13533.

[101] Qin, H.; Guan, X.; Bandstra J.Z.; Johnson R.L.; Tratnyek. P.G.. Environ. Sci.Technol. 2018, 52, 13887.

[102] Kim E.J.; Kim J.H.; Azad A.M.; Chang, Y.-S. Acs Appl. Mater. Inter. 2011, 3, 1457.

[103] Rajajayavel, S. R. C.; Ghoshal, S. Water Res. 2015, 78, 144.

[104] Li, J.; Zhang, X.; Liu, M.; Pan, B.; Zhang, W.; Shi, Z.; Guan, X. Environ. Sci. Technol. 2018, 52, 2988.

[105] Huang, S.; Xu, C.; Shao, Q.; Wang, Y.; Zhang, B.; Gao, B.; Zhou, W.; Tratnyek, P. G. Chem. Eng. J. 2018, 338, 539.

[106] He, F.; Li, Z.; Shi, S.; Xu, W.; Sheng, H.; Gu, Y.; Jiang, Y.; Xi, B. Environ. Sci. Technol. 2018, 52, 8627.

[107] Rossberg, A.; Ulrich, K.-U.; Weiss, S.; Tsushima, S.; Hiemstra, T.; Scheinost, A. C. Environ. Sci. Technol. 2009, 43, 1400.

[108] Kerisit, S.; Felmy, A. R.; Ilton, E. S. Environ. Sci. Technol. 2011, 45, 2770.

[109] Li, W.-L.; Troyer, L. D.; Lee, S. S.; Wu, J.-W.; Kim, C.; Lafferty, B. J.; Catalano, J. G.; Fortner, J. D. ACS Appl. Mater. Inter. 2017, 9, 13163.

[110] Skomurski, F. N.; Ilton, E. S.; Engelhard, M. H.; Arey, B. W.; Rosso, K. M. Geochim. Cosmochim. Ac. 2011, 75, 7277.

[111] Zhu, S.; Leng, Y.; Yan, M.; Tuo, X.; Yang, J.; Almásy, L.; Tian, Q.; Sun, G.; Zou, L.; Li, Q.; Courtois, J.; Zhang, H. Appl. Surf. Sci. 2018, 447, 381 .

[112] Qiu, M.-Q.; Wang, M.; Zhao, Q.-Z.; Hu, B.-W.; Zhu, Y.-L. Chemosphere 2018, 201, 764.

[113] Collins, R. N.; Rosso, K. M. J. Phys. Chem. A 2017, 121, 6603.

[114] Ma, B.; Fernandez-Martinez, A.; Kang, M.; Wang, K.; Lewis, A. R.; Maffeis, T. G. G.; Findling, N.; Salas-Colera, E.; Tisserand, D.; Bureau, S.; Charlet, L. Environ. Sci. Technol. 2020, 54, 8104.

[115] Dewey, C.; Sokaras, D.; Kroll, T.; Bargar, J. R.; Fendorf, S. Environ. Sci. Technol. 2020, 54, 6021.

[116] Jang, J.-H.; Dempsey, B. A.; Burgos, W. D. Water Res. 2008, 42, 2269.

[117] Yuan, K.; Renock, D.; Ewing, R. C.; Becker, U. Geochim. Cosmochim. Ac. 2015, 156, 194.

[118] Ilton, E. S.; Boily, J. F.; Buck, E. C.; Skomurski, F. N.; Rosso, K. M.; Cahill, C. L.; Bargar, J. R.; Felmy, A. R. Environ. Sci. Technol. 2010, 44, 170.

[119] Wander, M. C. F.; Kerisit, S.; Rosso, K. M.; Schoonen, M. A. A. J. Phys. Chem. A 2006, 110, 9691 .

[120] Latta, D. E.; Gorski, C. A.; Boyanov, M. I.; O’Loughlin, E. J.; Kemner, K. M.; Scherer, M. M. Environ. Sci. Technol. 2012, 46, 778

[121] Meinrath, G.; Kato, Y.; Kimura, T.; Yoshida, Z. Radiochim. Acta 1996, 75, 159.

[122] Langmuir, D. Geochim. Cosmochim. Ac. 1978, 42, 547.

[123] Grenthe, I.; Fuger, J.; Konings, R. J. M.; Lemire, R. J.; Muller, A. B.; Cregu, C. N.-T.; Wanner, H. J. Nucl. Mater. 1993, $200,154$.

[124] Jang, J.-H.; Dempsey, B. A.; Burgos, W. D. Water Res. 2006, 40, 2738.

[125] Cheng, T.; Barnett, M. O.; Roden, E. E.; Zhuang, J. Environ. Sci. Technol. 2004, 38, 6059.

[126] Mehta, V. S.; Maillot, F.; Wang, Z.; Catalano, J. G.; Giammar, D. E. Chem. Geol. 2014, 364, 66.

[127] Nico, P. S.; Stewart, B. D.; Fendorf, S. Environ. Sci. Technol. 2009, 43, 7391 .

[128] McBriarty, M. E.; Kerisit, S.; Bylaska, E. J.; Shaw, S.; Morris, K.; Ilton, E. S. Environ. Sci. Technol. 2018, 52, 6282.

[129] Marshall, T. A.; Morris, K.; Law, G. T. W.; Livens, F. R.; Mosselmans, J. F. W.; Bots, P.; Shaw, S. Environ. Sci. Technol. 2014, 48,3724 .

[130] McBriarty, M. E.; Soltis, J. A.; Kerisit, S.; Qafoku, O.; Bowden, M. E.; Bylaska, E. J.; De Yoreo, J. J.; Ilton, E. S. Environ. Sci. Technol. 2017, 51, 4970.

[131] Pullin, H.; Springell, R.; Parry, S.; Scott, T. Chem. Eng. J. 2017, $308,568$.

[132] Xu, H.; Sun, Y.; Li, J.; Li, F.; Guan, X. Environ. Sci. Technol. 2016, $50,8214$.

[133] Roh, Y.; Lee, S. Y.; Elless, M. P.; Foss, J. E. Clay Clay Miner. 2000, 
$48,266$.

[134] Stewart, B. D.; Nico, P. S.; Fendorf, S. Environ. Sci. Technol. 2009, 43, 4922.

[135] Roberts, H. E.; Morris, K.; Law, G. T. W.; Mosselmans, J. F. W.; Bots, P.; Kvashnina, K.; Shaw, S. Environ. Sci. Tech. Let. 2017, 4, 421.

[136] Klimkova, S.; Cernik, M.; Lacinova, L.; Filip, J.; Jancik, D.; Zboril, R. Chemosphere 2011, 82, 1178.

[137] Liesch, T.; Hinrichsen, S.; Goldscheider, N. Sci. Total Environ. 2015, 536,981 .

[138] Stumm, W. Chemistry of the Solid-Water Interface: Processes at the Mineral-Water and Particle-Water Interface in Natural Systems, Wiley, New York, 1992, pp. 309 325.

[139] Markich, S. J. Sci. World. J. 2002, 2, 707.

[140] Dong, W.; Brooks, S. C. Environ. Sci. Technol. 2006, 40, 4689.

[141] Lu, X.-C.; Wang, H.-M. Elements 2012, 8, 119.

[142] Cheng, Y.; Holman, H.-Y.; Lin, Z. Elements 2012, 8, 107.

[143] Abdelouas, A. Elements 2006, 2, 335.

[144] Liger, E.; Charlet, L.; Van Cappellen, P. Geochim. Cosmochim. Ac. 1999, 63, 2939.

[145] Wazne, M.; Korfiatis, G. P.; Meng, X.-G. Environ. Sci. Technol. 2003, 37, 3619.

[146] Villalobos, M.; Trotz, M. A.; Leckie, J. O. Environ. Sci. Technol. 2001, 35, 3849.

[147] Crane, R. A.; Dickinson, M.; Popescu, I. C.; Scott, T. B. Water Res. 2011, 45, 2931.

[148] Seder-Colomina, M.; Morin, G.; Brest, J.; Ona-Nguema, G.; Gordien, N.; Pernelle, J.-J.; Banerjee, D.; Mathon, O.; Esposito, G; van Hullebusch, E. D. Environ. Sci. Technol. 2015, 49, 14065.

[149] Du, X.; Boonchayaanant, B.; Wu, W.-M.; Fendorf, S.; Bargar, J.; Criddle, C. S. Environ. Sci. Technol. 2011, 45, 4718.

[150] Taylor, S. D.; Marcano, M. C.; Rosso, K. M.; Becker, U. Geochim. Cosmochim. Ac. 2015, 156, 154.

[151] Hu, S.-H.; Lin, X.-Y.; Zhao, W.-H.; Luo, X.-G. J. Radioanal. Nucl. Ch. 2018, 315, 223.

[152] Mehta, V. S.; Maillot, F.; Wang, Z.; Catalano, J. G.; Giammar, D. E. Environ. Sci. Technol. 2016, 50, 3128.

[153] Tang, G.; Luo, W.; Watson, D. B.; Brooks, S. C.; Gu, B. Environ. Sci. Technol. 2013, 47, 5787.
[154] Li, D.; Kaplan, D. I. J. Hazard. Mater. 2012, 243, 1.

[155] Missana, T.; García-Gutiérrez, M.; Fernńdez, V. Geochim. Cosmochim. Ac. 2003, 67, 2543.

[156] Waite, T. D.; Davis, J. A.; Payne, T. E.; Waychunas, G. A.; Xu, N Geochim. Cosmochim. Ac. 1994, 58, 5465.

[157] Millero, F. J. Am. Chem. Soc. 1990, 34, 447.

[158] Millero, F. J.; Izaguirre, M. J. Solution Chem. 1989, 18, 585.

[159] Missana, T.; Maffiotte, C.; García-Gutiérrez, M. J. Colloid Interf. Sci. 2003, 261, 154

[160] Lenhart, J. J.; Honeyman, B. D. Geochim. Cosmochim. Ac. 1999, 63, 2891.

[161] Sherman, D. M.; Peacock, C. L.; Hubbard, C. G. Geochim. Cosmochim. Ac. 2008, 72, 298.

[162] Moon, H. S.; Komlos, J.; Jaffé, P. R. Environ. Sci. Technol. 2007, 41, 4587.

[163] Liu, J.; Gu, T.-H.; Wang, W.; Liu, A.-R.; Zhang, W.-X. Acta Chim. Sinica 2019, 77, 121 (in Chinese). (刘静, 顾天航, 王伟, 刘爱荣, 张伟贤, 化学学报, 2019, 77, 121.)

[164] Scott, T. B.; Popescu, I. C.; Crane, R. A.; Noubactep, C. J. Hazard. Mater. 2011, 186, 280.

[165] Altmaier, M.; Gaona, X.; Fanghänel, T. Chem. Rev. 2013, 113, 901.

[166] Zanonato, P.; Di Bernardo, P.; Bismondo, A.; Liu, G.; Chen, X.; Rao, L. J. Am. Chem. Soc. 2004, 126, 5515

[167] Ji, Y. Colloid. Surface. A 2014, 444, 1.

[168] Tewari, P. H.; McLean, A. W. J. Colloid Interf. Sci. 1972, 40, 267.

[169] Environmental Protection Agency, National Primary Drinking Water Regulations, 2009, p. 6.

[170] World Health Organization, Guidelines for drinking-water quality: fourth edition incorporating first addendum, 4th ed. +1 st add ed., Geneva, 2017, p. 178 .

[171] Health Canada, Guidelines for Canadian Drinking Water Quality: Guideline Technical Document-Uranium, 1999, pp. 7 8.

[172] Umwelt Bundesamt, Uranium (U) in drinking water: Brief justification of the health limit value of the drinking water supply $(10 \mu \mathrm{g} / \mathrm{L}$ $\mathrm{U})$ and the limit value for "baby-appropriate" packaged water (2 $\mu \mathrm{g} / \mathrm{L} \mathrm{U}), 2013$, pp. $1 \sim 3$.

(Cheng, B.) 